\title{
Categorizing chairs and naming pears: Category differences in object processing as a function of task and priming
}

\author{
TOBY J. LLOYD-JONES \\ University of Kent, Canterbury, Kent, England \\ and \\ GLYN W. HUMPHREYS \\ University of Birmingham, Edgbaston, Birmingham, England
}

\begin{abstract}
Four experiments are reported examining the locus of structural similarity effects in picture recognition and naming with normal subjects. Subjects carried out superordinate categorization and naming tasks with picture and word forms of clothing, furniture, fruit, and vegetable exemplars. The main findings were as follows: (1) Responses to pictures of fruit and vegetables ("structurally similar" objects) were slowed relative to pictures of clothing and furniture ("structurally dissimilar" objects). This structural similarity difference was greater for picture naming than for superordinate categorization of pictures. (2) Structural similarity effects in picture naming were reduced by repetition priming. Repetition priming effects were equivalent from picture and word naming as prime tasks. (3) However, superordinate categorization of the prime did not produce the structural similarity effects on priming found for picture naming. Furthermore, such priming effects did not arise for picture or word categorization or for reading picture names as target tasks. It is proposed that structural similarity effects on priming object processing are located in processes mapping semantic representations of pictures to name representations required to select names for objects. Visually based competition between fruit and vegetables produces competition in name selection, which is reduced by priming the mappings between semantic and name representations.
\end{abstract}

Most current models propose that object naming may be decomposed into a series of processing stages, involving access to and retrieval of different kinds of stored information (e.g., Ellis \& Young, 1988; Humphreys, Riddoch, \& Quinlan, 1988; Seymour, 1979; Snodgrass, 1984; Warren \& Morton, 1982). Visual input is matched to a stored representation of the object's form (i.e., a structural representation). Access to the stored visual representation enables further access to conceptual and/or functional information about the object, and, subsequently, the object's name is retrieved. The distinction between these processing stages is supported by studies of normal object naming (e.g., Glaser, 1992; Riddoch \& Humphreys, 1987a; Seymour, 1979; Snodgrass, 1984) and by neuropsychological evidence of selective deficits in accessing different forms of stored information (e.g., Riddoch \& Humphreys, 1987b; Sheridan \& Humphreys, 1993). However, theories differ as to whether information transmission between stages operates continuously (i.e., partial information is passed on to a subsequent processing

This work was supported by Grants R-000-23-2412 and R-000-234279 from the Economic and Social Research Council of Great Britain to the second author. Correspondence should be addressed to T. J. Lloyd-Jones, Cognitive Neuroscience Research Centre, Department of Psychology, University of Kent, Canterbury, Kent CT2 7LZ, England (e-mail: t.j.lloyd-jones@ukc.ac.uk). stage; Humphreys et al., 1988; McClelland \& Rumelhart, 1981 ) or in a temporally discrete fashion (e.g., Levelt et al., 1991). Furthermore, it is not clear in what ways object processing may be constrained by the nature and category of object presented.

\section{Category Differences in Object Naming}

Neurological evidence of category-specific impairments-for example, in the recognition of living things (e.g., Farah, McMullen, \& Meyer, 1991; Riddoch \& Humphreys, 1987b; Sartori \& Job, 1988; Sartori, Job, \& M. Coltheart, 1993; Sheridan \& Humphreys, 1993; Silveri \& Gainotti, 1988)-demonstrate that category differences can arise in object recognition and identification (see Farah, 1990, Lloyd-Jones \& Humphreys, 1997, Riddoch \& Humphreys, 1987b, and Shallice, 1988, for reviews). Such impairments can be attributed to deficits at various functional loci in the object processing system. For example, in different cases, patients have been reported as having an impairment in their structural knowledge of animals and food (e.g., Sartori \& Job, 1988; Sartori et al., 1993; Silveri \& Gainotti, 1988) and an impairment in their functional knowledge of animals and food (Sheridan \& Humphreys, 1993).

Evidence from studies of normal object naming, however, suggests that category differences may arise due to processing differences between objects from different cate- 
gories and cannot solely be attributed to differential impairment of stored knowledge. Humphreys et al. (1988) and others (e.g., Lloyd-Jones \& Humphreys, 1997; Price \& Humphreys, 1989) have shown that objects from categories with many perceptually similar exemplars ("structurally similar" objects, such as fruit, vegetables, and animals) take longer to be named than do objects from categories with visually more distinctive exemplars ("structurally dissimilar" objects, such as clothing, furniture, and toys), even when the stimuli are matched for name frequency, complexity, and familiarity. LloydJones and Humphreys (1997) further found that differences between objects from different categories were larger in a naming task than in an object decision task (deciding whether the stimulus is an object or not) and that they were reduced by repetition priming (i.e., by subjects having seen the items earlier). Importantly, the effects of structural similarity on priming were equally large when subjects carried out object decisions to, or when they named, primes. We suggested that primes facilitate the process of visual differentiation of a target object from its perceptual neighbors, with differentiation being necessary to access stored structural representations of objects. Such a process is required for both object decision and naming tasks and is more difficult for structurally similar objects. The facilitation of visual differentiation leads to priming for naming in particular because naming involves processes additional to those mediating object decision, with there being repercussive or "knock-on" effects on these additional processes of (respectively) slow or facilitated visual differentiation (i.e., information transmission operates in a cascade-like fashion).

This, along with other recent work on normal object naming (e.g., Vitkovitch, Humphreys, \& Lloyd-Jones, 1993), suggests that one source of category differences in object identification is the process of perceptual differentiation between category members required to access stored structural representations of objects. Retrieval of semantic and name information for structurally similar objects suffers because such objects require relatively prolonged perceptual differentiation for identification to occur.

\section{Priming, Modality, and Task Influences on Object Naming}

Studies have shown strong within-modality repetition effects for both pictures and words (i.e., facilitation from having previously encountered the same concept in the same modality; e.g., Durso \& Johnson, 1979; Kirsner, Milech, \& Stumpfel, 1986; Warren \& Morton, 1982) and generally weaker cross-modality repetition effects (e.g., Durso \& Johnson, 1979; Kirsner et al., 1986; Scarborough, Gerard, \& Cortese, 1979; Warren \& Morton, 1982). Further converging evidence, such as cross-modality facilitation effects in associative priming (e.g., Carr, McCauley, Sperber, \& Parmalee, 1982; Guenther, Klatzky, \& Putnam, 1980; Sperber, McCauley, Regain, \& Weil, 1979;
Vanderwart, 1984), supports the view that (1) pictures and words access a common semantic representation and (2) pictures access this semantic representation directly from a structural representation, whereas words may access the semantic representation either directly (from an orthographic input representation) or indirectly after some amount of phonological processing has occurred (e.g., Bajo, 1988; M. Coltheart, 1985; Glaser \& Glaser, 1989; Morton \& Patterson, 1980; Nelson, Reed, \& McEvoy, 1977; Theios \& Amrhein, 1989).

Comparisons across tasks have shown that semantic decisions about category membership can be faster for pictures than for words but that naming is faster for words than for pictures (e.g., Potter \& Faulconer 1975; Rosch, 1975). Other investigators, however, have found inconsistent differences between the two forms (e.g., Durso \& Johnson, 1979; Smith \& Magee, 1980).

The few studies that have manipulated modality and task in the repetition priming paradigm suggest that some priming effects in picture naming may be located at a stage subsequent to semantic access (Durso \& Johnson, 1979; Wheeldon \& Monsell, 1992; cf. Warren \& Morton, 1982). For example, Wheeldon and Monsell (1992) found that picture naming was facilitated both when the name had been produced in response to a definition and when it had been read aloud. However, prior production of a homophone of the object's name did not prime picture naming. In a follow-up study, Monsell, Matthews, and Miller (1992), using Welsh-English bilinguals, found facilitation of picture naming from prior production of the name in response to definitions in the same language, but not from prior productions in the other language (provided that the equivalent other-language word differed in phonological form). Monsell et al. (1992) concluded from this that facilitation must be localized in the mappings between a word's meaning and its phonological form.

We have suggested that the process of picture name retrieval may be particularly difficult for categories of object whose exemplars share many perceptual features. It follows from this that we may expect category differences in priming name retrieval; in particular, priming should be most effective on the naming of structurally similar objects (such as fruit, vegetables, and animals).

\section{The Present Study}

The present paper is concerned with pinpointing the locus of category differences in the recognition and naming of objects. The objects were drawn from categories containing either many perceptually similar exemplars (structurally similar categories) or relatively few perceptually similar exemplars (structurally dissimilar categories) - fruit and vegetables on the one hand, and clothing and furniture on the other. Independent evidence that fruit and vegetables are more perceptually similar comes from measures of within-category contour overlap and number of partonomic features in common with 
other category members (Humphreys et al., 1988; see also Riddoch \& Humphreys, 1987b).

Structural similarity effects were investigated as a function of task, priming, and modality of presentation. Subjects either performed superordinate classification decisions (fruit vs. vegetables, and clothing vs. furniture) or named pictures of objects from these different categories. In addition, in both tasks, stimuli could be primed by their prior presentation in either the naming task or the categorization task. For both tasks, both primed and unprimed objects were represented in either their picture or their word (i.e., name) form. We assessed whether structural similarity effects were greater in naming than in categorization and whether they were greater for pictures than for words. We also assessed whether preactivating semantic knowledge (with categorization as the prime task) influenced any structural similarity effects in picture name retrieval and whether retrieval of the object's name (in naming) influenced any structural similarity effects in accessing semantic knowledge (in categorization). A difference in performance with pictures and words (e.g., with structural similarity effects on priming only arising with picture primes and targets) would suggest that any effects are located at a stage of processing unique to picture processing. In contrast, structural similarity effects on priming of equal magnitude from picture and word primes would suggest a locus in processes shared by both picture and word processing. For naming, this could be the semantic and/or phonological system or in the process mapping between the two; for categorization, this would most likely be the semantic system (since categorization does not require object name retrieval; see Vitkovitch \& Humphreys, 1991, for converging evidence).

In Experiment 1, subjects named pictures or words representing objects from the four categories (fruit, vegetables, clothing, and furniture) as primes and, subsequently, named pictures or words representing the same categories as targets. Experiments 2 and 3 employed the same design; however, for Experiment 2, the prime task was superordinate categorization (the target task remained naming), and, for Experiment 3, the prime task was naming and the target task superordinate categorization.

We predict slower naming of pictures of items from structurally similar categories compared with items from structurally distinct categories, due to the greater perceptual overlap of the former and, hence, their less efficient access to stored structural information. Differences between these two kinds of category may also be larger in picture naming than in picture categorization. Relative to categorization, picture naming involves the activation of more perceptual and semantic competitors, and, hence, it likely requires greater differentiation in order to perform the task. Competition from perceptual and semantic neighbors should be greater for fruit and vegetables than for clothing and furniture. For words, the predictions are less clear; however, in line with Job, Rumiati, and Lotto (1992), the visual and semantic similarity of fruit and vegetables may lead to slow categorization decisions for these categories compared with clothing and furniture.

\section{EXPERIMENT 1}

The main interest in Experiment 1 concerned picture targets. If priming arises due to semantic activation, priming for picture targets may be greater from pictures than from words, since picture but not word naming (for primes) should be semantically mediated (e.g., Bajo, 1988; M. Coltheart, 1985; Glaser \& Glaser, 1989; Morton \& Patterson, 1980; Nelson et al., 1977; Theios \& Amrhein, 1989). However, if priming arises due to prior activation of the names for objects (e.g., by activating the phonological output lexicon), priming should be equally large for word and picture primes, if words are pronounced lexically.

Most models of reading generally assume that words can be read aloud nonsemantically, as well as via semantic mediation, and that nonsemantic word naming can take place either by a direct lexical translation process or by nonlexical spelling-to-sound translation (e.g., Morton \& Patterson, 1980; Patterson \& V. Coltheart, 1987; although see Strain, Patterson, \& Seidenberg, 1995, for a different view). In order to provide some converging (although not definitive) evidence that word naming is lexically mediated, performance on words was compared with orthographically and phonologically matched nonwords. If words are named using the lexical route, their naming should be faster (McCann \& Besner, 1987; Patterson \& V. Coltheart, 1987).

\section{Method}

Except where mentioned otherwise, the same method was used in Experiments 2, $2 \mathrm{a}$, and 3.

Subjects. There were 64 subjects. All were paid members of the Birkbeck College subject pool, and all had normal or corrected-tonormal vision. All were native English speakers and had not seen the pictures before. Each subject participated in a single experimental session lasting about $40 \mathrm{~min}$.

Stimuli and Apparatus. Four semantic categories of object were used: clothing, furniture, fruit, and vegetables. There were 96 line drawings of objects (24 per category). Category exemplars were chosen from Rosch's (1975) norms and were selected from the whole range of typicality within each category. Drawings of objects were selected from the standardized set of Snodgrass and Vanderwart (1980), and added to these were further drawings by a trained artist (the first author). The creation of these additional drawings was constrained by the same criteria selected by Snodgrass and Vanderwart: (1) objects whose up-down orientation may vary (e.g., a fork) were drawn functional end down, (2) long thin objects were oriented at a $45^{\circ}$ angle with equal numbers in the two possible orientations, and (3) the objects were drawn so as to be of approximately equal size within and across category (so that objects in one category were not larger than those in another) based on the judgments of three independent judges.

Name agreement for the new drawings was assessed by presenting an independent group of 12 subjects with the complete set of potential stimuli. As with Snodgrass and Vanderwart (1980), each subject was shown each picture for a period of 3-5 sec and asked to write down the name of the object. If the subjects did not know the name, they were asked to mark one of the following categories: do 
not know name, do not know object, or tip-of-the-tongue. Following this procedure, only drawings of objects with greater than $75 \%$ name agreement were used. The complete list of stimuli is presented in the Appendix.

Frequency values for the names of each picture were obtained from Francis and Kučera's (1982) frequency analysis of English usage. Prototypicality ratings were obtained from Rosch's (1975) norms, and familiarity ratings were collected from 10 independent subjects using instructions similar to those used by Snodgrass and Vanderwart (1980). In addition, complexity ratings were gathered from 10 independent subjects, using instructions identical to those used by Snodgrass and Vanderwart. Table 1 gives the mean ratings on these measures for each category (i.e., structurally similar [fruits and vegetables] vs. structurally dissimilar [clothing and furniture items]. For complexity, familiarity, and name frequency, the higher the number, the more complex, familiar, and frequent. For prototypicality, the higher the number, the less prototypical the object. These ratings were subsequently used in analyses of covariance (ANCOVAs) of the data.

Lists of nonwords were constructed to match the word lists derived from the names of the pictured objects used. The words and nonwords were matched closely with respect to word length, number of syllables, and initial phoneme (altering initial consonants may change voice key sensitivity; see McCann \& Besner, 1987). This was achieved by changing at least one letter in each of the original words; more than one letter was changed if the nonword remained recognizable as derived from the original word (this was the case for long words, such as strawberry). In all cases, the initial phoneme in the new set of nonwords was identical to the initial phoneme of the original words.

Theios and Amrhein (1989) point out that, in order to have sensory equivalence, two foveally fixated stimuli must, at a minimum, be equated as much as possible in terms of the area they subtend on the retina. However, as regards pictures and words, few experimenters have done this. Thus, in the present series of experiments, pictures and words were equated in terms of size/visual angle. In order to make sure that this was the case in terms of mean width and range of widths, the average word length (six letters) was made $24 \mathrm{~mm}$ wide - the average picture width, with the largest and smallest pictures the same width as the largest and smallest words. Uppercase font was used.

The stimuli were presented using a two-field tachistoscope. Latencies in vocalizing were obtained by interfacing the tachistoscope with a crystal clock and voice-activated relay, such that the timing cycle began with the onset of the target stimulus and terminated with the subject's response. No masks were used.

Design and Procedure. There were four conditions where object concepts were represented in either their picture or their word forms. This combination was as follows: (1) picture prime-picture target, (2) picture prime-word target, (3) word prime-picture target, (4) word prime-word target. Thus, half of the 64 subjects received picture primes, and half received word primes; half of the 64 subjects received picture targets, and half received word targets. Words and matched nonwords were mixed within the same block.

To operationalize the experimental design, the 24 items from each category were divided into two equal lists (A and B) of 12 , pairwise matched (across means and ranges), in terms of name frequency $(\mathrm{NF}$ ) and prototypicality $(\mathrm{P})$ using the Francis and Kucera
(1982) and Rosch (1975) norms, respectively. The means were as follows: clothing, $A=16.6, B=16.9(\mathrm{NF})$, and $A=3, B=3(P)$; furniture, $A=30.7, B=28.4(N F)$, and $A=4, B=4(P)$; fruit, $A=$ $3.9, \mathrm{~B}=2.9(\mathrm{NF}$; this relatively large mean difference was caused by one item only-namely, lemon), and $\mathrm{A}=2.3, \mathrm{~B}=2.8$; vegetables, $\mathrm{A}=5.5, \mathrm{~B}=5.3(\mathrm{NF})$, and $\mathrm{A}=2.4, \mathrm{~B}=3.1(\mathrm{P})$.

For each condition, half of the 16 subjects received List $A$ of each category as the prime block (randomly ordered, with the constraint that each stimulus was not preceded by the same category on the previous 2 trials, to reduce intertrial priming) with Lists $A$ and $B$ as the target block. The other half received List B as the prime block and Lists $A$ and $B$ as the target block. Thus, for each group of subjects, half of the targets were primed and half were unprimed. The task for each subject was to name the prime (in the first block) and to name the target (in the second block). Each block lasted 15-20 min, and the second block immediately followed the first. For the picture stimuli, there were 20 practice trials, 48 prime trials, and 96 target trials; for word/nonword stimuli, there were 20 practice trials, 96 prime trials, and 192 target trials. Practice stimuli came from categories other than those used in the experimental trials and took place prior to the presentation of prime and target experimental blocks.

\section{Results}

The mean correct reaction times (RTs) were collated. A trial was scored an error if (1) the subject stuttered or misnamed the target, (2) the naming latency was 2 standard deviations (SDs) above or below the mean for that subject in that particular condition, or (3) a machine error occurred. Only trials falling into Categories 1 and 2 above were included in error analyses.

Responses to target trials where an error had been made to the picture on the corresponding prime trial were not excluded. This was because if such data were excluded, it may have resulted in the removal of object names that were intrinsically more "difficult" to produce, and since data from such names would be excluded from the primed but not the unprimed conditions, this might have resulted in an illusory priming effect. Including such data is a conservative procedure (see Wheeldon \& Monsell, 1992, for a discussion of this point).

The results for both by-subjects and by-items analyses are reported. For by-subjects analyses, the data were pooled for each subject over the various pictures presented in each combination of prime task $\times$ target task $\times$ category condition. For by-items analyses, the data in each condition were pooled for each picture over the various subjects who were presented with that picture in that condition. Subscripts 1 and 2 attached to an $F$ statistic refer to by-subjects and by-words analyses, respectively.

Furthermore, for all experiments, ANCOVAs were carried out on target task and baseline data, to establish that the main effects and interactions found were not due to

Table 1

Mean and $S D$ s for the Complexity (C), Familiarity (F), and Prototypicality (P) Ratings, and the Name Frequencies (NFs) for Each Category

\begin{tabular}{|c|c|c|c|c|c|c|c|c|}
\hline \multirow[b]{2}{*}{ Category } & \multicolumn{2}{|c|}{$\mathrm{C}$} & \multicolumn{2}{|c|}{$\mathrm{F}$} & \multicolumn{2}{|c|}{$\mathrm{P}$} & \multicolumn{2}{|c|}{ NF } \\
\hline & $M$ & $S D$ & $M$ & $S D$ & $M$ & $S D$ & $M$ & $S D$ \\
\hline 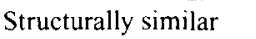 & 2.88 & 111 & 3.13 & 0.90 & 2.51 & 1.32 & 4.32 & 6.6 \\
\hline Structurally dissimilar & 3.01 & 0.85 & 4.10 & 0.59 & 3.46 & 1.82 & 25.20 & 31.1 \\
\hline
\end{tabular}


preexisting differences between the categories in terms of name frequency, ${ }^{1}$ prototypicality, and familiarity. In no case were the main effects or interactions qualified. Across all three experiments, there were two main effects arising from the ANCOVAs: (1) familiarity was a significant predictor of naming RT, and (2) prototypicality was a significant predictor of superordinate categorization RT. ${ }^{2}$

For the sake of clarity and simplicity, analyses were collapsed over fruit and vegetable items on the one hand and clothing and furniture items on the other. Thus, all analyses compare differences between structurally similar items (fruit and vegetables) and structurally dissimilar items (clothing and furniture). Three sets of analyses were conducted for each of the three experiments: analysis of prime task data, analysis of target task data (including a comparison of unprimed and primed items), and analysis of baselines alone (unprimed target task baseline items are the items that had not been presented during the prime task phase of the experiment). These analyses were carried out (1) to examine the extent to which there are structural similarity differences in the degree of priming that results from a prior encounter with the stimulus, (2) to ensure that any effects were due to priming and not a shift in baseline from one condition to another, and (3) to examine the extent to which there was priming in each of the prime-target task combinations (as distinct from structural similarity effects on priming).

Prime task analyses are reported first, followed by target task and baseline analyses. Word/nonword analyses are not reported, except for Experiment 1, where there was evidence of priming; in Experiments 2 and 3, responses were always faster and more accurate to words. Error analyses (using arcsine-transformed error data) are not reported since, in all cases, either there were no main effects or interactions or the same pattern emerged as for RTs. There was no evidence for a tradeoff between speed and accuracy.

Finally, for all experiments, two sets of confidence intervals were constructed using (1) the structural similarity difference scores, for each subject, that were entered into an analysis of variance (ANOVA) in order to obtain a mean square error $\left(M S_{\mathrm{e}}\right)$ value, which in turn was used as the basis of the confidence interval for the difference in priming effect between structurally similar and dissimilar categories, and (2) the priming difference scores that were entered into an ANOVA in order to obtain an $M S_{\mathrm{e}}$ value, which was used as the basis of the confidence interval for the priming effect within each condition (see Loftus \& Masson, 1994, for further details). The confidence intervals are given in Figures 1, 2, and 3, and the level of confidence in all cases was $95 \%$. (In these figures, the upper bars refer to Set 1 above, and the lower bars refer to Set 2 above.) These confidence intervals highlight which conditions produced reliable priming and for which conditions there were reliable structural similarity effects on priming.

The mean correct subject RTs, SDs, and percentage errors for each condition for the prime (naming) and target (naming) tasks are given in Tables 2 and 3, respec-

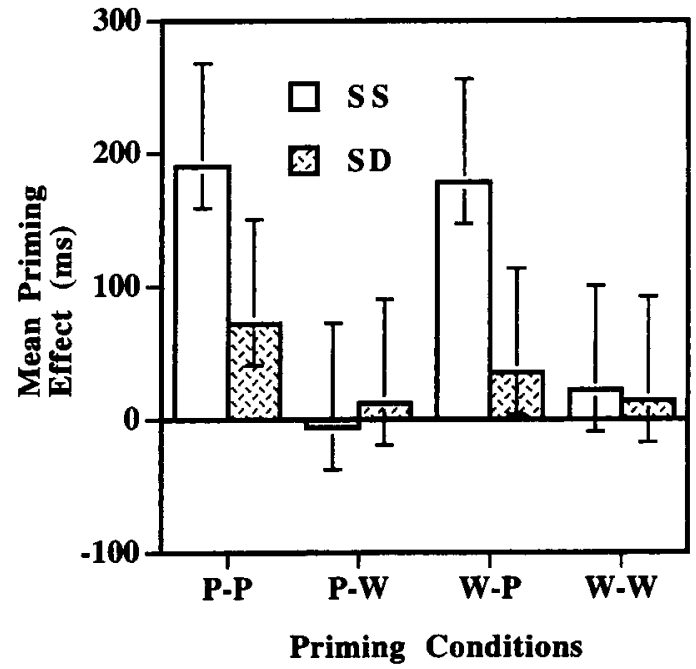

Figure 1. Mean priming effect and confidence intervals for naming as the target task in Experiment 1. Priming for picture and word targets, with greater priming for structurally similar picture targets than for structurally dissimilar picture targets, was robust by subject and by items.

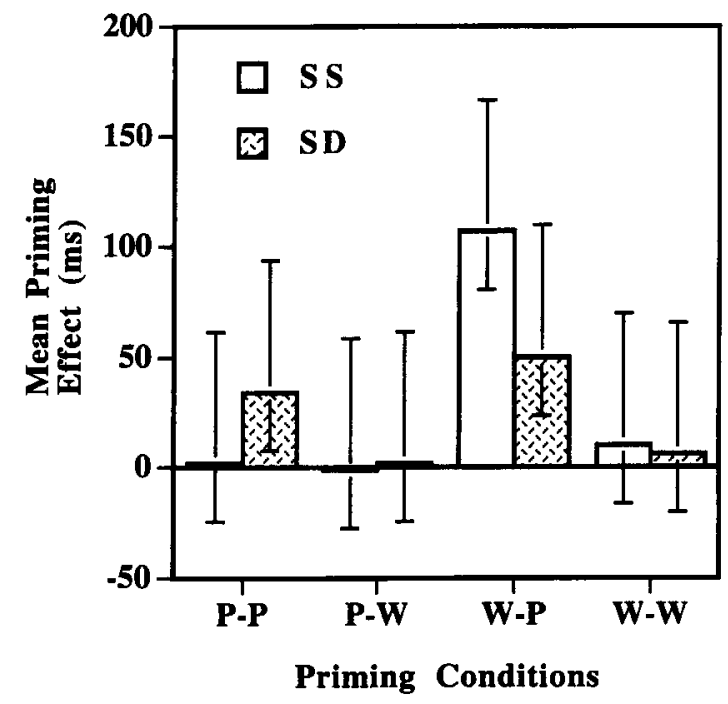

Figure 2. Mean priming effect and confidence intervals for naming as the target task in Experiment 2. Priming from word primes and for picture targets was significant by subjects only.

tively. Table 4 presents the mean correct subject RTs, $S D$ s, and percentage errors for the unprimed and primed word and nonword target task. Figure 1 gives the confidence intervals associated with the mean priming effect in each of the conditions of Experiment 1.

Prime task (naming). A three-way mixed ANOVA was carried out over the four conditions. The factors were prime modality (pictures vs. words), target modality (pictures vs. words), and category (structurally similar vs. structurally dissimilar items). The same analysis was carried out for Experiments 2 and 3. 


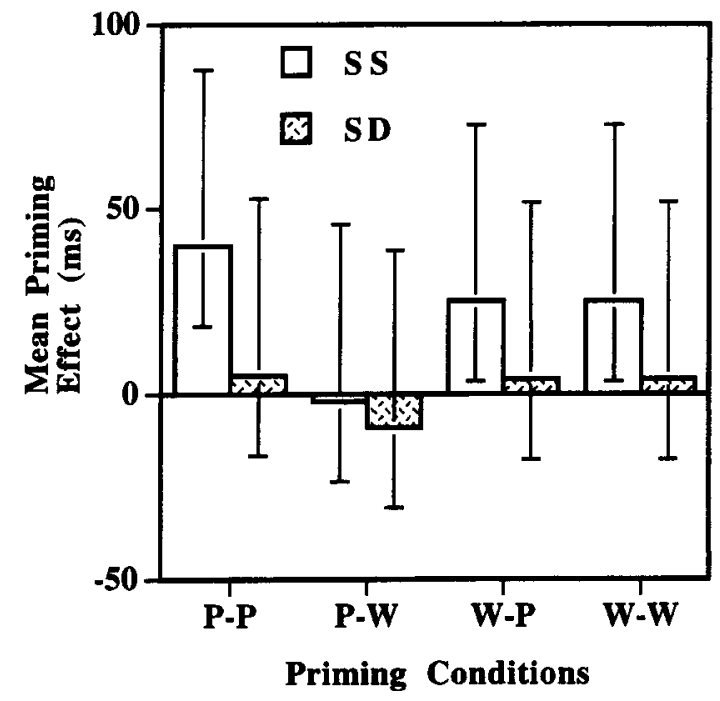

Figure 3. Mean priming effect and confidence intervals for categorization as the target task in Experiment 3. Priming for structurally similar targets was significant by items only.

There was a significant main effect of prime modality, with longer RTs to pictures than to words $\left[F_{1}(1,60)=\right.$ $357.66, M S_{\mathrm{e}}=16,717, p<.0001 ; F_{2}(1,94)=587.34$, $\left.M S_{\mathrm{e}}=33,534, p<.0001\right]$. There was a significant main effect of category, with longer RTs to structurally similar items than to structurally dissimilar items $\left[F_{1}(1,60)=\right.$ $161.55, M S_{\mathrm{e}}=5,423, p<.0001 ; F_{2}(1,94)=80.31, M S_{\mathrm{e}}=$ $38,191, p<.0001]$. Furthermore, there was a significant prime modality $\times$ category interaction $\left[F_{1}(1,60)=150.53\right.$, $M S_{\mathrm{e}}=5,423, p<.0001 ; F_{2}(1,94)=83.37, M S_{\mathrm{e}}=$ $33,534, p<.0001]$. The three-way prime modality $\times$ target modality $\times$ category interaction was marginally significant by items only $\left[F_{1}<1 ; F_{2}(1,94)=3.40, M S_{\mathrm{e}}=\right.$ $13,594, p=.068$ ].

The prime modality $\times$ category interaction was analyzed further using planned comparisons. For pictures as primes, RTs were longer to structurally similar items than to structurally dissimilar items $(p s<.01)$. For word primes, there was no significant difference.

Target task (naming). A four-way mixed ANOVA was carried out over the four conditions. The factors were prime modality (pictures vs. words), target modality (pictures vs. words), category (structurally similar vs. structurally dissimilar items), and priming (unprimed vs. primed). The same analysis was carried out for Experiments 2 and 3 .
There was a significant main effect of target modality, with longer RTs to pictures than to words $\left[F_{1}(1,60)=\right.$ $380.28, M S_{\mathrm{e}}=27,175, p<.0001 ; F_{2}(1,94)=557.13$, $\left.M S_{\mathrm{e}}=51,621, p<.0001\right]$. There was a significant main effect of category, with longer RTs to structurally similar items than to structurally dissimilar items $\left[F_{1}(1,60)=\right.$ $241.04, M S_{\mathrm{e}}=8,204, p<.0001 ; F_{2}(1,94)=82.08, M S_{\mathrm{e}}=$ $59,547, p<.0001]$. There was a significant main effect of priming, with longer RTs to unprimed items than to primed items $\left[F_{1}(1,60)=48.03, M S_{\mathrm{e}}=5,623, p<.0001\right.$; $\left.F_{2}(1,94)=95.82, M S_{\mathrm{e}}=7,691, p<.0001\right]$. Furthermore, there was a significant target modality $\times$ category interaction $\left[F_{1}(1,60)=288.44, M S_{\mathrm{e}}=8,204, p<.0001\right.$; $\left.F_{2}(1,94)=82.66, M S_{\mathrm{e}}=51,621, p<.0001\right]$ and a significant target modality $\times$ priming interaction $\left[F_{1}(1,60)=\right.$ $33.59, M S_{\mathrm{e}}=5,623, p<.0001 ; F_{2}(1,94)=66.01, M S_{\mathrm{e}}=$ $8,166, p<.0001]$. There was also a significant category $X$ priming interaction $\left[F_{1}(1,60)=7.09, M S_{\mathrm{e}}=8,797, p<\right.$ $\left..01 ; F_{2}(1,94)=27.45, M S_{\mathrm{e}}=7,691, p<.0001\right]$. Finally, there was a significant target modality $\times$ category $\times$ priming interaction $\left[F_{1}(1,60)=8.37, M S_{\mathrm{e}}=8,797, p<\right.$ $\left..01 ; F_{2}(1,94)=30.71, M S_{\mathrm{e}}=8,166, p<.0001\right]$.

The three-way target modality $\times$ category $\times$ priming interaction was analyzed further by carrying out separate ANOVAs for each target modality (pictures vs. words).

For pictures as targets, there was a significant main effect of category, with longer RTs to structurally similar items than to structurally dissimilar items $\left[F_{1}(1,31)=239.09\right.$, $M S_{\mathrm{e}}=15,404, p<.0001 ; F_{2}(1,94)=86.65, M S_{\mathrm{e}}=52,769$, $p<.0001]$. There was a significant main effect of priming, with longer RTs to unprimed items than to primed items $\left[F_{1}(1,31)=43.20, M S_{\mathrm{e}}=10,541, p<.0001 ; F_{2}(1,94)=\right.$ 84.23, $\left.M S_{\mathrm{e}}=7,528, p<.0001\right]$. Finally, there was a significant category $\times$ priming interaction $\left[F_{1}(1,31)=8.04\right.$, $M S_{\mathrm{e}}=16,884, p<.01 ; F_{2}(1,94)=30.62, M S_{\mathrm{e}}=7,528, p<$ $.0001]$. Planned comparisons showed a difference between unprimed and primed items for both structurally similar items ( $p<.01$, by subjects and by items) and structurally dissimilar items (marginally significant by subjects; $p<.01$, by items); however, the difference was greater for structurally similar items ( 184 vs. $53.5 \mathrm{msec}$ ).

For words as targets, there was a significant main effect of priming, with longer RTs to unprimed items than to primed items $\left[F_{1}(1,31)=6.47, M S_{\mathrm{e}}=558, p<.05\right.$; $\left.F_{2}(1,94)=9.64, M S_{\mathrm{e}}=400, p<.01\right]$. By subjects only, there was a significant main effect of category, with longer RTs to structurally similar items than to structurally dissimilar items $\left[F_{1}(1,31)=8.21, M S_{\mathrm{e}}=590, p<\right.$ $\left..01 ; F_{2}(1,94)=1.87\right]$.

Table 2

Mean RTs (in Milliseconds), SDs, and Percentage Errors (PEs) for the Prime Task (Naming) in Experiment 1

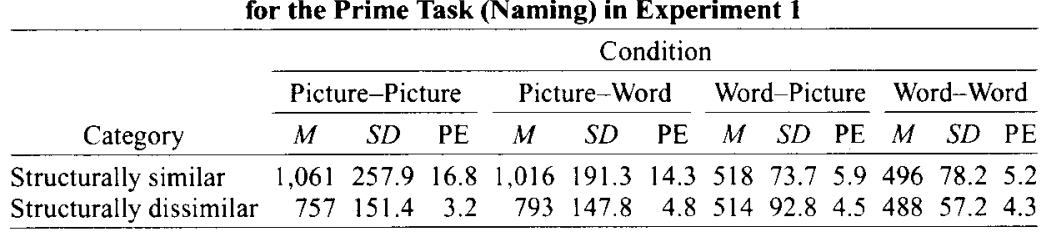


Table 3

\begin{tabular}{|c|c|c|c|c|c|c|c|c|c|c|c|c|}
\hline \multicolumn{13}{|c|}{$\begin{array}{c}\text { Mean RTs (in Milliseconds), SDs, and Percentage Errors (PEs) } \\
\text { for the Target Task (Naming) in Experiment } 1\end{array}$} \\
\hline \multirow[b]{3}{*}{ Category } & \multicolumn{12}{|c|}{ Condition } \\
\hline & \multicolumn{3}{|c|}{ Picture-Picture } & \multicolumn{3}{|c|}{ Picture-Word } & \multicolumn{3}{|c|}{ Word-Picture } & \multicolumn{3}{|c|}{ Word-Word } \\
\hline & $M$ & $S D$ & PE & $M$ & $S D$ & $\overrightarrow{\mathrm{PE}}$ & $M$ & $S D$ & PE & $M$ & $S D$ & $\mathrm{PE}$ \\
\hline \multicolumn{13}{|c|}{ Unprimed } \\
\hline Structurally similar & 1,174 & 228.2 & 15.2 & 522 & 74.5 & 5.3 & 1,172 & 155.6 & 18.2 & 517 & 106.3 & 4.5 \\
\hline Structurally dissimilar & 766 & 67.9 & 5.2 & 523 & 68.8 & 4.6 & 772 & 121.3 & 5.1 & 497 & 76.9 & 3.8 \\
\hline \multicolumn{13}{|c|}{ Primed } \\
\hline Structurally similar & 984 & 167.3 & 11.8 & 528 & 77.8 & 4.5 & 994 & 170.1 & 16.7 & 495 & 68.6 & 4.0 \\
\hline Structurally dissimilar & 694 & 72.7 & 5.4 & 511 & 57.6 & 4.6 & 737 & 97.6 & 3.3 & 483 & 57.9 & 5.1 \\
\hline
\end{tabular}

Baselines: Unprimed picture and word naming target task RT data. There were significant main effects of target modality, with longer RTs to pictures than to words $\left[F_{1}(1,60)=330.93, M S_{\mathrm{e}}=20,122, p<.0001\right.$; $\left.F_{2}(1,94)=703.61, M S_{\mathrm{e}}=26,416, p<.0001\right]$, and category, with longer RTs to structurally similar items than to structurally dissimilar items $\left[F_{1}(1,60)=128.41, M S_{\mathrm{e}}=\right.$ $10,679, p<.0001 ; F_{2}(1,94)=125.62, M S_{\mathrm{e}}=28,383$, $p<.0001]$. There was also a significant target modality $\times$ category interaction $\left[F_{1}(1,60)=116.74, M S_{\mathrm{e}}=10,679\right.$, $\left.p<.0001 ; F_{2}(1,94)=124.67, M S_{\mathrm{e}}=26,416, p<.0001\right]$. No other main effects or interactions were significant, including the three-way interaction $\left(F_{1}<1 ; F_{2}<1\right)$.

The target modality $\times$ category interaction was analyzed further using planned comparisons. For picture targets, RTs were longer to structurally similar items than to structurally dissimilar items ( $p$ s $<.01)$. For word targets, there was no significant difference.

Word versus nonword analyses. A mixed ANOVA was carried out on target task RTs. The factors were condition (picture-word vs. word-word), stimulus (word vs. nonword), and priming (unprimed vs. primed).

There was a main effect of priming, with longer RTs to unprimed items than to primed items $\left[F_{1}(1,30)=4.55\right.$, $M S_{\mathrm{e}}=1,167, p<.05 ; F_{2}(1,190)=12.78, M S_{\mathrm{e}}=2,275$, $p<.0005$ ], and a main effect of stimulus, with longer RTs to nonwords than to words $\left[F_{1}(1,30)=26.21\right.$, $M S_{\mathrm{e}}=9,889, p<.0001 ; F_{2}(1,190)=146.39, M S_{\mathrm{e}}=$ $10,426, p<.0001]$. Furthermore, there was a stimulus $X$ condition interaction $\left[F_{1}(1,30)=5.17, M S_{\mathrm{e}}=9,889, p\right.$ $\left.<.05 ; F_{2}(1,190)=110.24, M S_{\mathrm{e}}=2,974, p<.0001\right]$. By items, there was also a main effect of condition, with longer RTs to items in the picture-word condition than in the word-word condition $\left[F_{1}(1,30)=2.45 ; F_{2}(1,190)=\right.$ $\left.289.52, M S_{\mathrm{e}}=2,974, p<.0001\right]$. No other main effects or interactions were significant, including the three-way priming $\times$ stimulus $\times$ condition interaction (both $F_{1}$ and $F_{2}<1$ ).

\section{Discussion}

The main findings were as follows: There was a structural similarity difference for picture naming on unprimed baseline trials, with longer RTs to stimuli from structurally similar categories than to stimuli from structurally dissimilar categories. Furthermore, for pictures as targets, there was greater priming for structurally similar categories than for structurally dissimilar categories. This priming effect was equivalent for both pictures and words as primes. The ANCOVA showed that these effects remained strong after the effects of covariables had been partialed out.

In addition, (1) the lack of a structural similarity effect for the word-word condition argues against these effects being due to differences in letter or syllable length of the object names, and (2) the lack of a baseline shift confirms that the results are due to repetition priming, and not simply a shift in baselines between conditions.

The longer naming times for pictures of objects from categories with structurally similar exemplars (fruit and vegetables) relative to those from categories with structurally dissimilar exemplars (clothing and furniture) are consistent with visual similarity between picture and stored perceptual neighbors slowing identification time. Pictures of structurally similar objects showed greater priming than did those of structurally dissimilar objects. This is consistent with priming being a function of the degree of perceptual differentiation required to name target items (cf. Lloyd-Jones \& Humphreys, 1997) ${ }^{3}$

The present results suggest that structural similarity effects on priming may be located in processes shared by pictures and words in a naming task, where the effect of such priming is to facilitate picture naming (but not reading picture names). The possible locus of the structural similarity priming effect was investigated further in Experiment 2.

Finally, there was small but significant priming for words and nonwords, which was equivalent for the two

Table 4

Mean RTs (in Milliseconds), SDs, and Percentage Errors (PEs) for the Target Task (Words vs. Nonwords) in Experiment 1

\begin{tabular}{|c|c|c|c|c|c|c|}
\hline & \multicolumn{6}{|c|}{ Condition } \\
\hline & \multicolumn{3}{|c|}{ Picture-Word } & \multicolumn{3}{|c|}{ Word-Word } \\
\hline & $M$ & $S D$ & $\mathrm{PE}$ & $M$ & $S D$ & PE \\
\hline \multicolumn{7}{|l|}{ Unprimed } \\
\hline Word & 523 & 71.2 & 5.5 & 507 & 91.0 & 4.2 \\
\hline Nonword & 660 & 221.2 & 11.5 & 554 & 118.8 & 14.2 \\
\hline \multicolumn{7}{|l|}{ Primed } \\
\hline Word & 520 & 66.6 & 4.9 & 488 & 68.4 & 4.6 \\
\hline Nonword & 643 & 172.3 & 10.4 & 541 & 125.9 & 12.6 \\
\hline
\end{tabular}


classes of stimuli. In addition, priming was equivalent for both picture and word primes. Most researchers have distinguished lexical and nonlexical routes to pronunciation (e.g., M. Coltheart, 1980; Patterson \& Shewell, 1987). It is a key feature of such "dual-route" accounts that nonwords are read via a nonlexical route (i.e., via orthographic to phonological conversion procedures that operate independently of the lexicon). Words, on the other hand, may be read via any of the three possible routes: semantically, lexically, or nonlexically (although "regularization errors"-pronouncing pint as "hint," for example - may be made if irregular words are read using the nonlexical route). The difference in RTs and error rates between words and nonwords in the present experiment (with slower RTs and more errors to nonwords) suggests that words were read lexically (McCann \& Besner, 1987; Patterson \& V. Coltheart, 1987). If this is the case, any common source of priming for words and nonwords must be either at an initial stage of visual analysis or at a stage of accessing phonology (see, e.g., Ellis \& Young, 1988). The priming effect was equivalent when primes were pictures as well as when they were words; therefore, we must conclude that the repetition effect is located at the level of output phonology.

A different possibility is that priming was episodic (Jacoby, 1983). However, this extralexical source of facilitation is unlikely to be evident in RT paradigms at long lags, such as here (cf. Monsell, 1985). Moreover, the size of the repetition effect would be expected to differ according to context (i.e., whether the prime was a picture or a word), and this was not the case).

\section{EXPERIMENT 2}

In Experiment 2, subjects had to categorize primes and to name targets. Primes and targets again could be either pictures or words. The aims of the experiment were twofold: (1) to evaluate whether structural similarity differences arise in accessing semantic knowledge, assessed through the use of superordinate categorization with pictures and words, and (2) to evaluate the locus of the structural similarity effect on priming observed in Experiment 1 by assessing whether prior activation of the semantic representations of picture and/or word primes (in the categorization task) is sufficient to produce the structural similarity effects on priming found in picture naming.

Different structural similarity priming effects on picture naming may be expected from categorized picture and word primes, according to the locus of the repetition effects, and the kind of categorization task selected. For pictures, a living/nonliving decision could be based purely on a subset of perceptual features - for example, whether the shape has straight edges and/or geometric features versus fuzzy edges and an amorphous or irregular shape (Snodgrass \& McCullough, 1986). For words, access to semantic knowledge is required. Studies have also shown that superordinate categorization can be faster for stimuli from categories with visually similar exemplars than for stimuli from categories with visually more distinct exemplars (Price \& Humphreys, 1989; Riddoch \& Humphreys, 1987a). Such results are likely due to subjects' using perceptual information as diagnostic for picture categorization. For categories with visually distinct exemplars, superordinate categorization may need to be based on access to semantic information, since common perceptual features are more difficult to derive. Therefore, to ensure that semantic access was necessary for all categories and for both picture and word stimuli, Experiment 2 used a version of the superordinate categorization task where the choices were between either fruit and vegetables or clothing and furniture exemplars. In order to categorize fruit and vegetable pictures, subsets of visual features will be insufficient because of the perceptual overlap between exemplars across as well as within categories. For pictures of clothing and furniture, subsets of features common to all category members are more difficult to define in any case, so again recourse is likely needed to semantic categorical knowledge. For words, access to semantic knowledge is required, and visual similarity is not a confound.

The structural description system, the mappings between the structural description and semantic systems, and the semantic system itself are all possible loci of the differential effects of structural similarity on priming. If so, we may expect a replication of the priming effects from Experiment 1 on picture naming, when subjects have previously made a zategorization decision. For pictures as primes, structural knowledge will need to be activated to access the semantic knowledge needed for the categorization judgment. For words as primes, structural knowledge may be activated automatically following activation of category knowledge. The degree of activation within the structural description and semantic systems following word and picture primes is difficult to predict. Previous research does suggest, however, that semantic activation may be greater from pictures than from words (Caramazza, Hillis, Rapp, \& Romani 1990; Snodgrass \& McCullough, 1986).

Finally, even quite difficult classifications with pictures can be faster than picture naming (e.g., Price \& Humphreys, 1989). The differentiation between competitors at structural and semantic levels required to perform even difficult categorization tasks (such as fruit vs. vegetables) may not be as great as that required for naming. It follows that priming in general may be reduced relative to that in Experiment 1 .

\footnotetext{
Method

The method, design, and procedure were the same as in Experiment 1 , with one exception: The prime task was superordinate categorization, and the target task was naming. The subjects were given a choice of two verbal category labels prior to each trial: either clothing/furniture or fruit/vegetable (where one of the labels was correct and one incorrect). The order of category labels given was counterbalanced over subjects within conditions, and it was emphasized that both categories were equally likely to appear on each trial. Item presentation was rerandomized for each subject.
} 
There were 64 subjects selected from the Birkbeck College subject pool using the same criteria as in Experiment 1.

\section{Results}

Mean correct RTs and errors were collated for each condition. Error criteria were as in Experiment 1. The mean correct subject RTs, $S D$ s, and percentage errors for each condition for the prime (categorization) and target (naming) tasks are given in Tables 5 and 6, respectively. Prime task, target task, baseline, word/nonword, and error analyses were carried out as in Experiment 1 (word/nonword analyses are not reported). In addition, we also make a direct comparison of categorization and naming responses in order to contrast structural similarity differences across these two tasks. Figure 2 gives the confidence intervals associated with the priming effects in each condition and the effect of structural similarity on the amount of priming.

Prime task (categorization). A three-way mixed ANOVA was carried out over the four conditions. The factors were prime modality (pictures vs. words), target modality (pictures vs. words), and category (structurally similar vs. structurally dissimilar items).

By subjects and by items, there was a significant main effect of category, with longer RTs to structurally similar items than to structurally dissimilar items $\left[F_{1}(1,60)=\right.$ $15.34, M S_{\mathrm{e}}=7,459, p<.0005 ; F_{2}(1,94)=16.43, M S_{\mathrm{e}}=$ $22,710, p<.0001]$. There was a significant prime modality $\times$ category interaction $\left[F_{1}(1,60)=18.15, M S_{\mathrm{e}}=\right.$ $7,459, p<.0001 ; F_{2}(1,94)=31.15, M S_{\mathrm{e}}=12,384, p<$ $.0001]$. There was also a significant three-way prime modality $\times$ target modality $\times$ category interaction $\left[F_{1}(1,60)\right.$ $=7.29, M S_{\mathrm{e}}=7,459, p<.01 ; F_{2}(1,94)=7.62, M S_{\mathrm{e}}=$ $10,741, p<.01]$.

By items only, there was a significant main effect of prime modality, with longer RTs to word primes than to picture primes $\left[F_{1}(1,60)=1.25 ; F_{2}(1,94)=15.97\right.$, $\left.M S_{\mathrm{e}}=12,384, p<.0001\right]$, and a marginally significant main effect of target modality, with longer RTs for the groups that received picture targets than for those that received word targets $\left[F_{1}<1 ; F_{2}(1,94)=4.09, M S_{\mathrm{e}}=\right.$ $6,530, p=.045]$. Finally, by items, there was a marginally significant target modality $\times$ category interaction $\left[F_{1}<1 ; F_{2}(1,94)=4.54, M S_{\mathrm{e}}=6,530, p=.036\right]$.

The three-way prime modality $\times$ target modality $\times$ category interaction was analyzed further by carrying out separate ANOVAs for each prime modality (pictures vs. words).

For pictures as primes, there was a significant main effect of category, with longer RTs to structurally simi- lar items than to structurally dissimilar items $\left[F_{1}(1,30)=\right.$ $27.61, M S_{\mathrm{e}}=9,032, p<.0001 ; F_{2}(1,94)=50.07$, $\left.M S_{\mathrm{e}}=15,158, p<.0001\right]$. By items only, there was also a marginally significant main effect of target modality, with longer RTs for the group that subsequently received picture targets than for the group that subsequently receive word targets $\left[F_{1}<1 ; F_{2}(1,94)=4.80, M S_{\mathrm{e}}=10,035\right.$, $p=.031]$.

For words as primes, there was a significant target modality $\times$ category interaction $\left[F_{1}(1,30)=8.65, M S_{\mathrm{e}}=\right.$ $5,886, p<.01 ; F_{2}(1,94)=14.53, M S_{\mathrm{e}}=7,235, p<$ $.001]$. Further analysis of the target modality $\times$ category interaction using planned comparisons showed a crossover effect, with longer RTs to structurally similar items than to structurally dissimilar items for the group that subsequently received picture targets, but shorter RTs to structurally similar items than to structurally dissimilar items for the group that subsequently received word targets $(p s<.05)$. There were no other main effects or interactions.

Target task (naming). A four-way mixed ANOVA was carried out over the four conditions. The factors were prime modality (pictures vs. words), target modality (pictures vs. words), category (structurally similar vs. structurally dissimilar items), and priming (unprimed vs. primed).

There was a significant main effect of target modality, with longer RTs to picture targets than to word targets $\left[F_{1}(1,60)=379.53, M S_{\mathrm{e}}=29,652, p<.0001 ; F_{2}(1,94)=\right.$ 702.12, $\left.M S_{\mathrm{e}}=45,473, p<.0001\right]$. There was a significant main effect of category, with longer RTs to structurally similar items than to structurally dissimilar items $\left[F_{1}(1,60)=186.59, M S_{\mathrm{e}}=9,328, p<.0001 ; F_{2}(1,94)=\right.$ $\left.85.38, M S_{\mathrm{e}}=56,469, p<.0001\right]$. There was a main effect of priming, with longer RTs to unprimed items than to primed items, marginally significant by items $\left[F_{1}(1,60)\right.$ $=12.11, M S_{\mathrm{e}}=3,745, p<.001 ; F_{2}(1,94)=3.79, M S_{\mathrm{e}}=$ $10,886, p=.054]$. Furthermore, there was a significant target modality $\times$ category interaction $\left[F_{1}(1,60)=\right.$ $181.67, M S_{\mathrm{e}}=9,328, p<.0001 ; F_{2}(1,94)=93.30$, $\left.M S_{\mathrm{e}}=45,473, p<.0001\right]$. By subjects only, there was a significant prime modality $\times$ priming interaction $\left[F_{1}(1,60)=5.06, M S_{\mathrm{e}}=3,745, p<.05 ; F_{2}<1\right]$ and a target modality $\times$ priming interaction $\left[F_{1}(1,60)=8.47\right.$, $\left.M S_{\mathrm{e}}=3,745, p<.01 ; F_{2}(1,94)=1.66\right]$. No other main effects or interactions were significant.

Further analysis of the target modality $\times$ category interaction using planned comparisons showed longer RTs to structurally similar pictures than to structurally dissimilar pictures (a difference of $327.7 \mathrm{msec} ; p s<.01$ );

Table 5

Mean RTs (in Milliseconds), $S D$ s, and Percentage Errors (PEs) for the Prime Task (Categorization) in Experiment 2

Condition

\begin{tabular}{|c|c|c|c|c|c|c|c|c|c|c|c|c|}
\hline \multirow[b]{3}{*}{ Category } & \multicolumn{12}{|c|}{ Condition } \\
\hline & \multicolumn{3}{|c|}{ Picture-Picture } & \multicolumn{3}{|c|}{ Picture-Word } & \multicolumn{3}{|c|}{ Word-Picture } & \multicolumn{3}{|c|}{ Word-Word } \\
\hline & $M$ & $S D$ & PE & $M$ & $S D$ & PE & $M$ & $S D$ & PE & $M$ & $S D$ & PE \\
\hline Structurally similar & 854 & 103.3 & 10.9 & 857 & 226.8 & 11.5 & 857 & 142.8 & 5.9 & 797 & 170.7 & 9.8 \\
\hline Structurally dissimilar & 755 & 122.5 & 5.3 & 706 & 110.1 & 8.0 & 806 & 111.4 & 8.5 & 859 & 131.5 & 7.6 \\
\hline
\end{tabular}


Table 6

Mean RTs (in Milliseconds), $S D$ s, and Percentage Errors (PEs) for the Target Task (Naming) in Experiment 2

\begin{tabular}{|c|c|c|c|c|c|c|c|c|c|c|c|c|}
\hline \multirow[b]{3}{*}{ Category } & \multicolumn{12}{|c|}{ Condition } \\
\hline & \multicolumn{3}{|c|}{ Picture-Picture } & \multicolumn{3}{|c|}{ Picture-Word } & \multicolumn{3}{|c|}{ Word-Picture } & \multicolumn{3}{|c|}{ Word-Word } \\
\hline & $M$ & $S D$ & PE & $M$ & $S D$ & PE & $M$ & $S D$ & $\mathrm{PE}$ & $M$ & $S D$ & $\mathrm{PE}$ \\
\hline \multicolumn{13}{|c|}{ Unprimed } \\
\hline Structurally similar & 1,065 & 103.6 & 17.3 & 511 & 75.1 & 5.9 & 1,182 & 223.5 & 15.5 & 520 & 59.3 & 5.3 \\
\hline Structurally dissimilar & 777 & 89.2 & 11.5 & 514 & 65.6 & 5.1 & 802 & 135.8 & 9.3 & 513 & 58.7 & 4.8 \\
\hline \multicolumn{13}{|c|}{ Primed } \\
\hline Structurally similar & 1,063 & 208.2 & 17.2 & 512 & 61.0 & 4.9 & 1,075 & 202.7 & 14.2 & 510 & 55.4 & 6.4 \\
\hline Structurally dissimilar & 743 & 110.1 & 7.2 & 512 & 61.7 & 5.5 & 752 & 104.1 & 9.4 & 507 & 63.7 & 3.3 \\
\hline
\end{tabular}

however, it showed no difference between structurally similar and structurally dissimilar words. Further analysis of the prime modality $\times$ priming interaction by subjects showed longer RTs to unprimed items than to primed items previously seen as words (a difference of $43 \mathrm{msec}$; $p$ s <.01). There was no difference between unprimed and primed items previously seen as pictures. Finally, further analysis of the target modality $\times$ priming interaction by subjects showed longer RTs to unprimed picture targets than to primed picture targets (a difference of $48.2 \mathrm{msec}$ ). There was no difference between unprimed and primed word targets.

Baselines: Unprimed picture and word naming target task RT data. There was a significant main effect of target modality, with longer RTs to picture targets than to word targets $\left[F_{1}(1,60)=365.87, M S_{\mathrm{e}}=17,056, p<\right.$ $\left..0001 ; F_{2}(1,94)=919.44, M S_{\mathrm{e}}=18,156, p<.0001\right]$. There was also a significant main effect of category, with longer RTs to structurally similar items than to structurally dissimilar items $\left[F_{1}(1,60)=100.92, M S_{\mathrm{e}}=8,967\right.$, $\left.p<.0001 ; F_{2}(1,94)=89.06, M S_{\mathrm{e}}=23,236, p<.0001\right]$. Finally, there was a significant target modality $\times$ category interaction $\left[F_{1}(1,60)=98.15, M S_{\mathrm{e}}=18,967, p<\right.$ $\left..0001 ; F_{2}(1,94)=99.01, M S_{\mathrm{e}}=18,156, p<.0001\right]$. No other main effects or interactions were significant.

Further analysis of the target modality $\times$ category interaction using planned comparisons showed longer RTs to structurally similar picture targets than to structurally dissimilar picture targets $(p<.01)$. For word targets, there was no significant difference.

Comparison of categorization and naming. RTs were longer to structurally similar pictures than to structurally dissimilar pictures for both categorization (with primes) and naming (e.g., with unprimed baseline targets). Analyses confirmed that the structural similarity difference was greater for naming than for categorization. ${ }^{4}$

\section{Discussion}

In contrast to the results of Experiment 1 (when the prime task was naming), superordinate categorization of the prime in either its picture form or its word form produced no structural similarity effects on priming picture naming as a target task. There was greater priming from words as primes and for pictures as targets; however, these effects were not robust over items as well as over subjects.
We performed power analyses to determine whether the power of the ANOVA in Experiment 2 was sufficient to detect main effects or interactions across priming conditions, using significant effect sizes from Experiment 1 as the basis for power estimates. There is no general formula for calculating mixed ANOVA effect sizes (i.e., $f 2$ values; cf. Erdfelder, Faul, \& Buchner, 1996). Therefore, to calculate values of $f$, we used the mean square value for the main effect of target modality with the appropriate $M S_{\mathrm{e}}$ value from ANOVAs on the data from Experiment 1, with prime and target modality as factors, and structural similarity and priming difference scores as the dependent variables. By subjects, with a Type I error rate of .05 , power estimates were $1.00(f=$ $2.89)$ and $1.00(f=5.78)$ for structural similarity and priming scores, respectively. By items, with a Type I error rate of .05 , the estimate was the same, $1.00(f=$ 7.84) with priming difference scores as the dependent variable (see Cohen 1988; Erdfelder et al., 1996). ${ }^{5}$ These analyses also hold for Experiment 3.

Categorization responses to primes. For pictures, RTs were consistently longer to vegetables and fruit than to clothing and furniture. For words, structural similarity effects were less robust.

Longer RTs to categorize pictures of fruit and vegetables support the structural similarity effects found in an object decision task by Lloyd-Jones and Humphreys's (1997) Experiment 2 and also the effects in naming in Experiment 1 of the present study. This object decision task demanded the rejection of nonobjects formed by interchanging the parts of real objects, requiring stored structural knowledge of the objects to be used for the decisions (see Riddoch \& Humphreys, 1987b; Sheridan \& Humphreys, 1993). Assuming that the clothing/furniture categorization task here required access to semantic information, the fact that the fruit/vegetable categorization took significantly longer strongly suggests that this task too was based on access to semantic information. Furthermore, the overall RTs for pictures in the three tasks show a trend found across previous experiments (Price \& Humphreys, 1989; Riddoch \& Humphreys, 1987a). Object decision RTs were shortest $(M=666 \mathrm{msec}$, over categories in Lloyd-Jones \& Humphreys, 1997, Experiment 2), categorization RTs longer ( $M=793 \mathrm{msec}$, over categories in the present experiment), and naming RTs 
longest $(M=990 \mathrm{msec}$, over categories in Lloyd-Jones \& Humphreys, 1997, Experiment 2, and $M=956 \mathrm{msec}$, over categories in the present experiment). These results are also consistent with the categorization task involving access to semantic information, rather than being performed on the basis of some coarse perceptual structural/featural information.

The data on RTs to categorize primes suggest that access to sufficient semantic information necessary to perform the task is faster for clothing and furniture pictures. This is consistent with the argument made earlier that, for exemplars from structurally similar categories (i.e., fruit and vegetables), more competitor features/objects at the perceptual level are activated, making the category differentiation more difficult for these exemplars. Yet, category effects here on picture categorization were smaller than in the picture naming data in Experiment 1 (an overall difference of $125 \mathrm{msec}$, between fruit/vegetables and clothing/furniture in picture classification vs. an overall difference of $334 \mathrm{msec}$, for naming). This suggests that perceptual competition generates further and greater competition at the name retrieval stage of object processing over and above effects at a semantic level. Such perceptual competition is more severe for fruit and vegetables than for clothing and furniture.

Finally, it is of note also that, for clothing and furniture, the categorization data replicate the results of previous studies showing faster categorization for pictures than for words. The pictorial advantage for clothing and furniture here was $102 \mathrm{msec}$. In contrast, for fruit and vegetables, no pictorial advantage was apparent. The lack of a pictorial advantage for fruit and vegetables fits with their greater visual similarity relative to that of clothing and furniture, which specifically lengthens picture categorization RTs.

However, one caveat is necessary when discussing the pure RTs to picture categorization. Unlike the clothing/ furniture categorization, the fruit/vegetable categorization confounds within- and across-category similarity. Acrosscategory similarity may have contributed to categorization RTs for fruits and vegetables. We return to this point in the General Discussion section.

The priming effect. Given that superordinate categorization involved semantic access for both pictures and words, the lack of a structural similarity priming effect on picture naming from categorization as the prime task suggests that the location of structural similarity effects on priming is in processes subsequent to access and retrieval of the semantic knowledge required to perform the categorization decision. For both decisions, but for the fruit/vegetable picture discrimination in particular, categorization likely involved access to item-specific semantic information. We propose, therefore, that the process of mapping from a semantic representation of an object to its name representation is the most plausible locus of the structural similarity priming effects in picture naming. Hence, the effects are confined to picture naming as a target task, and they arise from naming as a prime task. The trend toward a structural similarity priming effect for categorized word primes onto picture naming is not inconsistent with this proposal; word categorization may have involved changes in the mappings between phonological output and semantic representations. In part, this may occur because words automatically access corresponding stored phonological representations, and these, once activated, can lead in turn to the activation of semantic information and activation of semantic-name mappings. Such an account is also needed to explain strong structural similarity priming effects on picture naming from word primes in Experiment 1.

In Experiment 2a, we sought to clarify whether the trend toward greater priming for structurally similar pictures relative to that for structurally dissimilar pictures, when preceded by word primes, was a real or spurious effect.

\section{Experiment 2a}

Experiment 2a replicated the word prime-picture target condition of Experiment 2. The same method, design, and stimuli as in Experiment 2 were used, with 16 new subjects who had not seen the pictures before. The only difference between this replication and Experiment 2 was that words and pictures were now presented on a Macintosh LC computer, using the Psychlab software package of Bub and Gum (1988). One effect of using Psychlab was to shorten the intertrial interval. Thus, the overall lag between prime and target was shorter; the average experiment duration was $15 \mathrm{~min}$, relative to the 30 min of Experiments 1 and 2. This would, if anything, be expected to produce stronger priming effects, since there is much evidence that repetition priming increases with a decrease in time between prime and target (Monsell, 1985). Words and pictures were presented in black on a white background and were the same size as those in Experiments 1 and 2.

\section{Results}

Mean correct RTs and errors were collated for each condition. Error criteria were the same as those in Experiments 1 and 2. The mean correct subject RTs, $S D$ s, and percentage errors for each condition are given in Table 7 . The analyses for Experiment 2a are reported below. In addition, to provide a more powerful test of the hypothesis, we combined the data from the target task word prime-picture target condition of Experiment 2 with the target task data from Experiment 2a.

\section{Experiment 2a Analyses}

For the prime task (word categorization) data, an ANOVA was carried out, with category (structurally similar vs. structurally dissimilar) as the factor. There was no main effect by subjects or by items.

For the target task (naming) data, a two-way ANOVA was carried out. The factors were category (structurally similar vs. structurally dissimilar) and priming (unprimed vs. primed). There was a significant main effect of category, with longer RTs to structurally similar items than 
Table 7

Mean RTs (in Milliseconds), SDs, and Percentage Errors (PEs) for the Prime Task (Word Categorization) and the Target Task (Picture Naming) in Experiment 2a

\begin{tabular}{|c|c|c|c|c|c|c|c|c|c|}
\hline \multirow[b]{3}{*}{ Category } & & & & \multicolumn{6}{|c|}{ Picture Naming } \\
\hline & \multicolumn{3}{|c|}{ Word Categorization } & \multicolumn{3}{|c|}{ Unprimed } & \multicolumn{3}{|c|}{ Primed } \\
\hline & $M$ & $S D$ & PE & $M$ & $S D$ & PE & $M$ & $S D$ & $\mathrm{PE}$ \\
\hline Structurally similar & 850 & 170.0 & 6.6 & 1,214 & 216.6 & 10.0 & 1,162 & 125.8 & 8.7 \\
\hline Structurally dissimilar & 841 & 142.1 & 6.1 & 1,011 & 63.7 & 7.5 & 979 & 105.8 & 6.0 \\
\hline
\end{tabular}

to structurally dissimilar items $\left[F_{1}(1,15)=19.83, M S_{\mathrm{e}}=\right.$ $30,109, p<.001 ; F_{2}(1,94)=39.47, M S_{\mathrm{e}}=88,686$, $p<.0001]$. No other main effects or interactions were significant.

Finally, for the baseline data (i.e., unprimed picture and word naming target RT data), an ANOVA, with category (structurally similar vs. structurally dissimilar) as the factor, was carried out. There was a significant main effect, with longer RTs to structurally similar items than to structurally dissimilar items $\left[F_{1}(1,15)=13.88, M S_{\mathrm{e}}=23,818\right.$, $\left.p<.005 ; F_{2}(1,94)=30.43, M S_{\mathrm{e}}=59,663, p<.0001\right]$.

\section{Combining the Data From Experiments 2 and 2a}

A three-way mixed ANOVA was carried out. The factors were experiment ( 2 vs. 2a), category (structurally similar vs. structurally dissimilar), and priming (unprimed vs. primed).

There was a significant main effect of experiment, with longer RTs in Experiment 2a than in Experiment 2 $\left[F_{1}(1,30)=13.96, M S_{\mathrm{e}}=44,409, p<.001 ; F_{2}(1,94)=\right.$ $\left.133.38, M S_{\mathrm{e}}=33,517, p<.0001\right]$. There was a significant main effect of category, with longer RTs to structurally similar items than to structurally dissimilar items $\left[F_{1}(1,30)=92.51, M S_{\mathrm{e}}=25,674, p<.0001 ; F_{2}(1,94)=\right.$ $\left.84.58, M S_{\mathrm{e}}=93,032, p<.0001\right]$. There was a significant main effect of priming, with longer RTs to unprimed items than to primed items $\left[F_{1}(1,30)=10.83, M S_{\mathrm{e}}=\right.$ $10,820, p<.01 ; F_{2}(1,94)=4.07, M S_{\mathrm{e}}=29,566, p<$ $.05]$. Finally, by subjects only, there was a significant experiment $\times$ category interaction $\left[F_{1}(1,30)=7.82, M S_{\mathrm{e}}=\right.$ $\left.25,674, p<.01 ; F_{2}<1\right]$. Further analysis of the experiment $\times$ priming interaction using planned comparisons showed a greater difference between structurally similar and structurally dissimilar items for Experiment 2 than for Experiment $2 \mathrm{a}(p \mathrm{~s}<.01)$. No other main effects or interactions were significant.

\section{Discussion}

There was clearly no structural similarity effect on priming, even though there was a strong baseline difference between structurally similar and structurally dissimilar items. We have replicated the null effect of Experiment 2; categorizing a word prime does not produce an effect of structural similarity on priming picture naming. This was the case, even though the interval between prime and target was shortened (relative to that of Experiments 1 and 2), which may have been expected to increase the size of any priming effects, if present. Moreover, this remained the case when we combined the data from Experiments 2 and 2a, using 32 subjects in all to provide a more powerful test of the hypothesis.

\section{EXPERIMENT 3}

In Experiment 3, the prime task was naming and the target task superordinate categorization. From Experiments 2 and 2a, we conclude that priming results from access to item-specific information, most likely realized within the semantic-name mappings. From this, we predict the following. Superordinate categorization of pictures does not require mapping from semantic to name information. Thus, we expect no effect of structural similarity on priming for the categorization of picture targets, when subjects have previously named pictures or read the picture name. For word categorization, predictions are less clear. We have proposed that, for words, there can be automatic access to name representations and subsequent effects on semantic-name mappings. Nevertheless, if such effects occur "off-line," then word categorization as an "on-line" task should not be primed by picture naming; nor should differential effects emerge on contrasting categories of objects. Performance should be similar to that with picture categorization as the target task.

\section{Method}

The method, design, and procedure were the same as those in Experiments 1 and 2, except that the prime task was naming and the target task was superordinate categorization. There were 64 subjects selected from the Birkbeck College subject pool using the same criteria as for the previous experiments.

\section{Results}

Mean correct RTs and errors were collated for each condition. Error criteria were the same as those in Experiment 1 . The mean correct subject RTs, SDs, and percentage errors for each condition for the prime (naming) and target (categorization) tasks are given in Tables 8 and 9, respectively. Figure 3 gives the confidence intervals associated with the priming effect in each condition and the effect of structural similarity on the amount of priming.

Prime task (naming). A three-way mixed ANOVA was carried out over the four conditions. The factors were prime modality (pictures vs. words), target modality (pictures vs. words), and category (structurally similar vs. structurally dissimilar items).

There was a significant main effect of prime modality, with longer RTs to pictures than to words $\left[F_{1}(1,60)=\right.$ $326.09, M S_{\mathrm{e}}=18,017, p<.0001 ; F_{2}(1,94)=628.43$, 
Table 8

\begin{tabular}{|c|c|c|c|c|c|c|c|c|c|c|c|c|}
\hline \multirow[b]{3}{*}{ Category } & \multicolumn{12}{|c|}{ Condition } \\
\hline & \multicolumn{3}{|c|}{ Picture-Picture } & \multicolumn{3}{|c|}{ Picture-Word } & \multicolumn{3}{|c|}{ Word-Picture } & \multicolumn{3}{|c|}{ Word-Word } \\
\hline & $M$ & $S D$ & PE & $M$ & $S D$ & $\mathrm{PE}$ & $M$ & $S D$ & $\mathrm{PE}$ & $M$ & $S D$ & PE \\
\hline Structurally similar & 1,112 & 198.8 & 12.1 & 1,108 & 182.7 & 10.0 & 539 & 57.4 & 4.3 & 525 & 69.6 & 6.9 \\
\hline Structurally dissimilar & 789 & 117.4 & 9.4 & 782 & 85.2 & 10.2 & 529 & 54.4 & 5.7 & 514 & 63.1 & 4.2 \\
\hline
\end{tabular}

$\left.M S_{\mathrm{e}}=30,754, p<.0001\right]$. There was a significant main effect of category, with longer RTs to structurally similar items than to structurally dissimilar items $\left[F_{1}(1,60)=\right.$ $190.76, M S_{\mathrm{e}}=5,011, p<.0001 ; F_{2}(1,94)=90.39$, $\left.M S_{\mathrm{e}}=36,775, p<.0001\right]$. Furthermore, there was a significant prime modality $\times$ category interaction $\left[F_{1}(1,60)=\right.$ $171.12, M S_{\mathrm{e}}=5,011, p<.0001 ; F_{2}(1,94)=95.75$, $\left.M S_{\mathrm{e}}=30,754, p<.0001\right]$. There were no other main effects or interactions.

The prime modality $\times$ category interaction was analyzed further using planned comparisons. For pictures as primes, RTs to structurally similar items were longer than those to structurally dissimilar items $(p s<.01)$. For word primes, there was no significant difference.

Target task (categorization). A four-way mixed ANOVA was carried out over the four conditions. The factors were prime modality (pictures vs. words), target modality (pictures vs. words), category (structurally similar vs. structurally dissimilar items), and priming (unprimed vs. primed).

There was a significant main effect of category, with longer RTs to structurally similar items than structurally dissimilar items $\left[F_{1}(1,60)=42.08, M S_{\mathrm{e}}=7,612, p<\right.$ $\left..0001 ; F_{2}(1,94)=26.35, M S_{\mathrm{e}}=28,159, p<.0001\right]$. Furthermore, there was a significant target modality $\times$ category interaction $\left[F_{1}(1,60)=25.24, M S_{\mathrm{e}}=7,612, p<\right.$ $\left..0001 ; F_{2}(1,94)=73: 93, M S_{\mathrm{e}}=10,167, p<.0001\right]$. Further analysis of the target modality $x$ category interaction using planned comparisons showed longer RTs to structurally similar picture targets than to structurally dissimilar picture targets $(p s<.01)$. For word targets, there was no significant difference.

By items only, there was a significant main effect of target modality, with longer RTs to word targets than to picture targets $\left[F_{1}<1 ; F_{2}(1,94)=8.39, M S_{\mathrm{e}}=10,167\right.$, $p<.005]$, and a main effect of priming (marginally significant by subjects), with longer RTs to unprimed items than to primed items $\left[F_{1}(1,60)=3.27, M S_{\mathrm{e}}=2,693\right.$, $\left.p=.076 ; F_{2}(1,94)=7.01, M S_{\mathrm{e}}=4,647, p<.01\right]$. By items only, there was also a marginally significant target modality $\times$ priming interaction $\left[F_{1}(1,60)=1.24\right.$; $\left.F_{2}(1,94)=3.84, M S_{\mathrm{e}}=5,616, p=.053\right]$. Finally, by items alone, there was a significant category $\times$ priming interaction $\left[F_{1}(1,60)=2.88, M S_{\mathrm{e}}=2,492, p=.094\right.$; $\left.F_{2}(1,94)=6.64, M S_{\mathrm{e}}=4,647, p<.01\right]$ and a marginally significant prime modality $\times$ target modality $\times$ category interaction $\left[F_{1}<1 ; F_{2}(1,94)=3.62, M S_{\mathrm{e}}=4,879, p=\right.$ $.060]$. Further analysis of the by-item category $\times$ priming interaction using planned comparisons showed longer RTs to unprimed structurally similar items than to primed structurally similar items $(p<.01)$. There was no priming for structurally dissimilar items.

Baselines: Unprimed picture and word categorization target task RT data. There was a significant main effect of category $\left[F_{1}(1,60)=41.26, M S_{\mathrm{e}}=5,133, p<\right.$ $\left..0001 ; F_{2}(1,94)=27.64, M S_{\mathrm{e}}=19,462, p<.0001\right]$. Furthermore, there was a significant category $\times$ target modality interaction $\left[F_{1}(1,60)=21.20, M S_{\mathrm{e}}=5,133, p<\right.$ $\left..0001 ; F_{2}(1,94)=44.05, M S_{\mathrm{e}}=10,077, p<.0001\right]$. No other main effects or interactions were significant.

Further analysis of the category $\times$ target modality interaction using planned comparisons showed longer RTs to structurally similar picture targets than to structurally dissimilar picture targets $(p s<.01)$. For word targets, there was no significant difference.

\section{Discussion}

When superordinate categorization was the target task (and naming was the prime task), there were no robust structural similarity effects on priming. There were trends

Table 9

Mean RTs (in Milliseconds), SDs, and Percentage Errors (PEs) for the Target Task (Categorization) in Experiment 3

\begin{tabular}{|c|c|c|c|c|c|c|c|c|c|c|c|c|}
\hline & \multicolumn{12}{|c|}{ Condition } \\
\hline & \multicolumn{3}{|c|}{ Picture-Picture } & \multicolumn{3}{|c|}{ Picture-Word } & \multicolumn{3}{|c|}{ Word-Picture } & \multicolumn{3}{|c|}{ Word-Word } \\
\hline & $M$ & $S D$ & $\mathrm{PE}$ & $M$ & $S D$ & PE & $M$ & $S D$ & PE & $M$ & $S D$ & $\mathrm{PE}$ \\
\hline \multicolumn{13}{|c|}{ Unprimed } \\
\hline Structurally similar & 901 & 168.6 & 9.6 & 861 & 158.8 & 7.3 & 911 & 153.5 & 7.9 & 851 & 158.0 & 6.7 \\
\hline Structurally dissimilar & 762 & 123.0 & 5.2 & 842 & 146.0 & 5.8 & 771 & 114.6 & 6.6 & 824 & 140.9 & 8.5 \\
\hline
\end{tabular}


for greater priming for pictures and for structurally similar items, but not for structurally dissimilar items. However, both results were found for the item analysis only.

For categorized pictures, baselines were longer to fruit and vegetables than to clothing and furniture. For categorized words, there were no significant baseline differences.

\section{GENERAL DISCUSSION}

The main results of interest from Experiments 1-3 concern the effects of structural similarity on different tasks and on priming picture naming.

First, there were longer RTs to fruit and vegetables than to clothing and furniture for superordinate categorization and naming of pictures. However, structural similarity differences were greater for picture naming than for categorization. For word categorization and naming, there were no clear structural similarity differences.

These longer RTs to pictures of fruit and vegetables, for both categorization and naming tasks, are consistent with within-category visual similarity slowing down access to stored structural, semantic, and name representations. We suggest the structural similarity effect is larger on naming than on categorization because naming may require finer perceptual differentiation between category members, and slowed access to semantic information will enable the names of more semantic neighbors to be activated. Consistent with this proposal is evidence in the literature that (1) picture naming involves semantic mediation (e.g., Glaser \& Glaser, 1989; Theios \& Amrhein, 1989; Warren \& Morton, 1982), (2) the naming of objects from structurally similar categories shows greater effects of semantic mediation than does the naming of objects from structurally dissimilar categories (Humphreys et al., 1988; Riddoch \& Humphreys, 1987a), (3) there is greater activation of semantic neighbors for objects from categories with visually similar exemplars (Vitkovitch et al., 1993), and (4) effects of within-category similarity can be simulated in an interactive-activation and competition model of object naming, whereby high visual similarity between category members produces strong competition at structural, semantic, and name levels. Due to this competition, accessing specific semantic information is relatively difficult, and the process of selecting a name is yet more difficult (Humphreys, Lamote, \& LloydJones, 1995; Lloyd-Jones, Humphreys, \& Brockdorff, 1995, 1997).

Longer categorization RTs to fruits and vegetables are unlikely to be due to semantic similarity between these items alone, since there were no reliable structural similarity differences on categorization responses to words (contrary to Job et al., 1992). However, a further factor that may have contributed to the longer RTs to fruits and vegetables is the across-category similarity between the stimuli, which could have affected performance in addition to any effects of within-category similarity (cf. Job et al., 1992; Snodgrass \& McCullough, 1986). Acrosscategory similarity between fruits and vegetables was likely higher than that between clothing and furniture.
One consequence of this is that, in effect, more category members were presented for the former stimuli. Kroll and Stewart (1994) have shown that there is category interference in picture naming when same-category members are named in a blocked (relative to mixed) list. However, it is unlikely that the effects due to the similarity of items across different categories was a major contributing factor here. In a 1995 unpublished study, ${ }^{6}$ we compared naming performance to structurally similar and dissimilar items, with and without additional same category "fillers." List context effects slightly exaggerated the category difference, but they were not a major factor.

Nevertheless, a different categorization comparison, such as fruit/clothing and vegetable/furniture, may not have yielded longer RTs to fruit and vegetables. As we suggested in the introduction to Experiment 2, this is most probably because categorization for fruits and vegetables, in this case, could be based on perceptual information, since individual exemplars share considerable perceptual overlap (see Price \& Humphreys, 1989, for such a result). A better comparison might be fruit/vegetables versus kitchen utensil/tools, for example. With acrosscategory similarity better equated, and when the categorization task requires item-specific semantic differentiation, our account would still predict longer RTs to structurally similar categories due to their greater withincategory similarity. We have proposed that partial activation is transmitted from one stage to another during processing, and, as a result, objects with greater structural similarity within their classes produce further and greater activation of structurally and semantically related objects (which results in the activation of the phonological representations of the target, perceptually and semantically related neighbors, and, possibly, items phonologically related to semantically related objects). When the task requires differentiating between competing targets, as in categorization and naming here, this competition at structural, semantic, and name levels lengthens RT for structurally similar objects. In contrast, however, when responses can be based on information computed across category, such as in a fruit/clothing categorization, visual similarity can facilitate task performance (Lloyd-Jones et al., 1995).

The second, and more important, result is that differential effects of structural similarity on priming (with greater priming for fruit and vegetables relative to clothing and furniture) arose only when subjects named pictures (not when they read picture names or categorized pictures or words), following the previous naming of pictures or words. In two experiments, categorization of the prime produced no effects of structural similarity on priming picture naming. There were also no effects on word naming. Note here that overall statistical power for Experiments 2 and 3 was above the desirable power level of .8 advocated by Cohen (1965). From this we propose that the locus of the category-specific repetition priming effects in object naming is the semantic-name mappings. Object naming, but not object categorization, requires 
such mappings to be used, whereas the output phonological representations themselves are eliminated as a locus because structural similarity effects were not apparent in word naming.

Naming reflects processes in addition to categorization (in particular, semantic information must be mapped onto corresponding names), and, in the present experiments, these processes were particularly influenced by repetition priming from prior naming of stimuli. This is because prior naming leads to changes in the mappings between semantic and name information, facilitating subsequent name retrieval for target pictures with the same names as primes. We have proposed that initial naming times are slow because visual and semantic similarity increases competition for name selection for these stimuli. It is this competition that specifically is decreased by the previous naming of primes. Our proposal provides a parsimonious explanation of both the slow naming RTs and the structural similarity effects on priming naming, and it accounts for why the magnitudes of the effects vary as a function of the prime and target tasks (e.g., why structural similarity effects on priming do not occur with categorization as either the prime or the target task).

One potential caveat needs to be mentioned, however, before accepting this argument fully. In Experiments 2 and $2 \mathrm{a}$, there were no structural similarity effects on priming picture naming with categorization as the prime task; however, in Experiment 3 (naming then categorizing), there was a trend toward more priming for categorizing structurally similar items with subjects having named either pictures or words previously. This would suggest a different locus to the category priming effect-namely, the semantic system. However, the result was true by items, but not by subjects: Only half of the 64 subjects showed greater priming for structurally similar items than for structurally dissimilar items in Experiment 3. Furthermore, the mean difference in priming between structural categories was $22.2 \mathrm{msec}$, a considerably smaller difference than that of $130.5 \mathrm{msec}$ found in Experiment 1 . Given the power calculations, we consider this structural similarity difference to be spurious.

Finally, we note that previous studies typically find greater within-modality (e.g., picture-picture), as opposed to across-modality (e.g., word-picture), repetition priming (e.g., Lachman \& Lachman, 1980; Weldon \& Roediger, 1987; see Roediger \& Srinivas, 1993, for a review). These results have been interpreted as support for either the priming of pictures being mediated by a structural description system (see Schacter, 1990, and below) or a "transfer-appropriate processing" approach, whereby memory performance is facilitated according to the extent to which cognitive processes engaged at test match those engaged at study (see, e.g., Roediger \& Srinivas, 1993). Most of these studies used a mixed-list (within-subject) format. However, using pure lists of either pictures or words, Brown, Neblett, Jones, and Mitchell (1991) found equivalent priming from pictures and words on picture naming. The present study also used a pure-list format. Therefore, one possible explanation of the discrepancy (put forward by Brown et al.) is that greater priming for the picture-picture condition in earlier studies using a mixed-list format depends on subjects' attention being drawn to the perceptual format of stimuli during the study phase. Park and Gabrieli (1995), however, have found an advantage for picture primes (relative to word primes, and where priming occurred for both) on picture naming in a pure-list study - a superiority that remained despite changes in list format, stimulus materials, and study-phase procedures, and regardless of whether the prime task was picture naming or picture identification. Park and Gabrieli suggest that the pure-list design may have inflated word-picture priming in Brown et al.'s study, reflecting explicit or episodic memory processes (since Brown et al. combined picture naming and recognition judgment tasks in the test phase). Such an explanation seems unlikely here given (1) the lack of implicit/explicit task combination, (2) the long lag between study and test phases, (3) the large number of intervening items, (4) the small amount of time between trials for spontaneous elaborative encoding, and (5) the fact that subjects did not expect repetitions (cf. Monsell, 1985). Indeed, Park and Gabrieli's advantage for picture priming may reflect superior explicit memory for pictures: Compared with the present experiment, for example, their experiments used a much shorter lag between study and test phases and contained substantially fewer intervening items.

One other explanation for the discrepancy between within- and across-modality priming is that, unlike the present study, almost all previous studies have used large pictures and small words, confounding perceptual discriminability. Equating size and featural line width (and number of response alternatives), Theios and Amrhein (1989) found equivalent within- and across-modality priming for pictures and words (there was also a strong stimulus size effect, with small stimuli taking longer to be processed). Park and Gabrieli (1995) report using a lowercase 24-point font, but neither they nor Brown et al. (1991) report picture size/visual angle.

One result that fits less easily with the present proposal (for structural similarity effects on priming located in name retrieval) is that reported by Lloyd-Jones and Humphreys (1997) in their related study. Lloyd-Jones and Humphreys found no difference between object decision and picture naming as prime tasks in their influence on the naming of target pictures and found that both prime tasks reduced the magnitude of the structural similarity effects on picture naming. This result, with object decision as the prime task, stands in contrast to the absence of structural similarity priming effects from semantic categorization onto picture naming in Experiment 2 here. This suggests either of two possibilities. One is that the results occurred because object decisions require access to more specific stored knowledge than semantic categorization. For example, semantic categorization may still be possible when there is partial activation of several object representations, providing they correspond to objects from the same category; this may not hold for ob- 
ject decisions, where nonobjects may partially activate object representations. Object naming also requires access to specific object representations; however, for object naming, specific information is required at the semantic and name levels as well as at the level of structural descriptions. Priming may be enhanced whenever specific object representations are preactivated in the priming task; also, objects from categories with structurally similar exemplars may benefit most because access to specific object representations is particularly difficult for such objects. Thus, enhanced structural similarity effects on priming may arise following access to specific object representations at structural, semantic, and name levels, since this may alter the mappings between these representations to favor particular targets.

Two other results are relevant here. First, we found evidence of priming in Experiments 2 and 3: categorizing pictures and words primed picture naming in Experiment 2 (by subjects; marginally nonsignificant by items), and naming pictures and words primed picture categorization in Experiment 3 (by items; marginally nonsignificant by subjects). Second, Vriezen, Moscovitch, and Bellos (1995) have recently found priming for both pictures and words in a forced two-choice semantic categorization task (e.g., "Is it man-made?"). These results suggest that the lack of structural similarity effects on priming for categorization onto naming in Experiment 2 was not simply because priming generally requires subjects to specify the target object, and categorization in the present case did not involve this. It also argues against the lack of structural similarity effects on priming being due to the fact that categorization solely involved the use of perceptual cues to discriminate between categories. We have suggested that categorization here involves access to item-specific semantic information (at least for fruits and vegetables). Nevertheless, we cannot rule out the possibility that a different kind of categorization task-perhaps accessing "deeper" semantic knowledge (e.g., soft vs. hard vegetable) - would produce structural similarity effects on priming picture naming. It is worth noting that other researchers have found similar difficulties in producing repetition priming in tasks that require objects to be categorized (e.g., living/nonliving, inside/outside the house), even though these categorizations should involve (at least) the reactivation of structural descriptions and access to semantic knowledge (Bruce \& Humphreys, 1994).

The second possibility is that, in the object decision task used by Lloyd-Jones and Humphreys (1997), subjects named objects, having made the object decision (object decision responses were considerably faster than naming responses, suggesting that any implicit naming was not on-line during performance of the task). This would produce changes in mappings between semantic and name representations, facilitating the naming of repeated pictures. Again, any facilitation would be greatest for objects from categories with structurally similar exemplars, since these objects produce the greatest competition for name selection.
A different suggestion is that the greater priming for structurally similar items arose because of their longer initial baseline RTs per se, irrespective of the processes involved in the prime and target tasks. We argue against this because, in Experiments 2 and 2a, baseline naming times were slower to structurally similar items than to structurally dissimilar items, yet there was no enhanced priming of structurally similar items. Furthermore, across conditions, baseline RTs to name structurally similar items do not predict the magnitude of priming. ${ }^{7}$

We believe the present results with fruits and vegetables generalize to other categories whose exemplars are perceptually similar. Consistent with this, a control experiment in Lloyd-Jones and Humphreys (1997) replicated the picture naming-picture naming condition used here in all respects, but with a broader range of semantically unrelated categories. Furthermore, our account of category differences arising at a relatively late level in picture naming (at a level of name selection)-and yet with problems for particular categories being precipitated by visual relationships between stimuli-may also help explain at least some category-specific deficits in the neuropsychological literature. For example, Farah and Wallace (1992) reported the case of a patient with a specific deficit in naming fruit and vegetables (see also Hart, Bernt, \& Caramazza, 1985). The problem for this patient seemed confined to naming and did not affect object recognition: The patient was able to retrieve considerable semantic information about visually presented fruit and vegetables that he could not name. In addition, the impairment in naming fruit and vegetables was not confined to visual presentation but also occurred with spoken definitions and in a verbal fluency task. Within our account, such a result could emerge from selective damage to the retrieval process needed for object naming, which we have shown to be particularly difficult for the naming of fruit and vegetables even for normal subjects. One reason we initially selected fruit and vegetables as stimuli was because the degree of contour overlap for these items is among the highest of all the categories in Snodgrass and Vanderwart (1980). Assuming structural similarity to be a continuum, neuropsychological deficit, in certain cases, may be expected to affect just those categories with the highest structural similarity.

In conclusion, category specificity in neuropsychological cases does not necessarily indicate a structural difference in the representation of specific categories of item. Processing differences between categories, which exist in normality, can also contribute.

\section{REFERENCES}

BaJo, M.-T. (1988). Semantic facilitation with pictures and words. Journal of Experimental Psychology: Learning, Memory, \& Cognition, 4, 579-589.

Brown, A. S., Neblett, D. R., Jones, T. C., \& Mitchell, D. B. (1991) Transfer of processing in repetition priming: Some inappropriate findings. Journal of Experimental Psychology: Learning, Memory, \& Cognition, 17, 514-525.

Bruce, V., \& Humphreys, G. W. (1994). Recognizing objects and faces. Visual Cognition, 1, 141-180. 
Bub, D., \& Gum, T. (1988). Psychlab (Version 0.85) [Computer program]. Montreal: Author.

Caramazza, A., Hillis, A. E., Rapp, B. C., \& Romani, C. (1990). The multiple semantics hypothesis: Multiple confusions? Cognitive Neuropsychology, 7, 161-189.

Carr, T. H., McCauley, C., Sperber, R. D., \& Parmalee, C. M. (1982). Words, pictures and priming: On semantic activation, conscious identification and the automaticity of information processing. Journal of Experimental Psychology: Human Perception \& Performance, 8, 757-777.

COHEN, J. (1965). Some statistical issues in psychological research. In B. B. Wolman (Ed.), Handbook of clinical psychology (pp. 95-121). New York: McGraw-Hill.

COHEN, J. (1988). Statistical power analyses for the behavioural sciences. New York: Academic Press.

Coltheart, M. (1980). Reading, phonological recoding and deep dyslexia. In M. Coltheart, K. E. Patterson, \& J. Marshall, Deep dyslexia (pp. 326-380). London: Routledge and Kegan Paul.

Coltheart, M. (1985). Cognitive neuropsychology and the study of reading. In M. I. Posner \& O. S. M. Marin (Eds.), Attention and performance $X I$ (pp. 3-37). Hillsdale, NJ: Erlbaum.

Durso, F. T., \& JoHnson, M. K. (1979). Facilitation in naming and categorizing repeated pictures and words. Journal of Experimental Psychology: Human Learning \& Memory, 5, 449-459.

Ellis, A., \& Young, A. (1988). Human cognitive neuropsychology. London: Erlbaum.

ERdFELDER, E., FAUL, F., \& BuChNer, A. (1996). GPOWER: A general power analysis program. Behaviour Research Methods, Instruments, \& Computers, 28, 1-11.

FARAH, M. J. (1990). Visual agnosia: Disorders of object recognition and what they tell us about normal vision. Cambridge, MA: MIT Press.

Farah, M. J., McMullen, P. A., \& Meyer, M. M. (1991). Can recognition of living things be selectively impaired? Neuropsychologia, $\mathbf{2 9}$, 185-193.

Farah, M. J., \& Wallace, M. A. (1992). Semantically-bounded anomia: Implications for the neural implementation of naming. Neuropsychologia, 30, 609-621.

Francis, W. N., \& KučERA, H. (1982). Computational analyses of present-day American English. Providence, RI: Brown University.

Glaser, W. R. (1992). Picture naming. Cognition, 42, 61-105.

Glaser, W. R., \& Glaser, M. O. (1989). Context effects in Stroop-like word and picture processing. Journal of Experimental Psychology. General, 118, 13-42.

Guenther, R. K., Klatsky, R. L., \& Putnam, W. (1980). Commonalities and differences in semantic decisions about pictures and words. Journal of Verbal Learning \& Verbal Behavior, 19, 54-74.

Hart, J., Bernt, R. S., \& Caramazza, A. (1985). Category-specific naming deficit following cerebral infarction. Nature, 316, 439-440.

Humphreys, G. W., Lamote, C., \& Lloyd-Jones, T. J. (1995). An interactive activation approach to object proessing: Effects of structural similarity, name frequency, and task in normality and pathology Memory, 3, 535-586.

Humphreys, G. W., Riddoch, M. J., \& Quinlan, P. T. (1988). Cascade processes in picture identification. Cognitive Neuropsychology, $\mathbf{5}$, 67-103.

JACOBY, L. L. (1983). Perceptual enhancement: Persistent effects of an experience. Journal of Experimental Psychology: Learning, Memory, \& Cognition, 9, 21-38.

Joв, R., Rumiati, R., \& LotTo, L. (1992). The picture superiority effect in categorization: Visual or semantic. Journal of Experimental Psychology: Learning, Memory, \& Cognition, 18, 1019-1028.

KirSner, K., Milech, D., \& STumpFel, V. (1986). Word and picture identification: Is representational parsimony possible? Memory \& Cognition, 14, 398-408.

KOELE, P. (1982). Calculating power in analysis of variance. Psychological Bulletin, 92, 513-516.

KROLL, J. F., \& STEWART, E. (1994). Category interference in translation and picture naming: Evidence for asymmetric connections between bilingual memory representations. Journal of Memory \& Language, 33, 149-174.

Lachman, R., \& Lachman, J. L. (1980). Picture naming: Retrieval and activation of long-term memory: Proceedings of the George A. Talland Memorial Conference. In L. W. Poon, J. L. Fozard, L. S. Cermak, D. Arnberg, \& L. W. Thompson (Eds.), New directions in memory and aging (pp. 313-343). Hillsdale, NJ: Erlbaum.

Levelt, W. J. M., Schriefers, H., Vorberg, D., Meyer, A. S., PechMANN, T., \& Havinga, J. (1991). The time course of lexical access in speech production: A study of picture naming. Psychological Review, 98, 122-142

Lloyd-Jones, T. J., \& Humphreys, G. W. (1997). Perceptual differentiation as a source of category effects in object processing: Evidence from naming and object decision. Memory \& Cognition, 25, 18-35.

Lloyd-Jones, T. J., Humphreys, G. W., \& BrockdorfF, N. (1995). Modelling object processing: Converging evidence from human experimental and computational modelling perspectives. In R. MorenoDíaz \& J. Mira-Mira (Eds.), Brain processes, theories and models (pp. 96-102). Cambridge, MA: MIT Press.

LLOYD-JoNes, T. J., HumPHREYS, G. W., \& BRoCKDORFF, N. (1997). Visual similarity effects on learning to name and categorize novel objects: An experimental and computational study. Manuscript submitted for publication

LofTUS, G. R., \& MAsson, M. E. J. (1994). Using confidence intervals in within-subject designs. Psychological Bulletin \& Review, 1, 476-490.

MCCANN, R. S., \& BESNER, D. (1987). Reading pseudohomophones: Implications for models of pronunciation assembly and the locus of word frequency effects in naming. Journal of Experimental $P_{\text {sychol- }}$ ogy: Human Perception \& Performance, 13, 14-24.

MCClelland, J. L., \& Rumelhart, D. A. (1981). An interactive activation model of context effects in letter perception: Part 1. An account of basic findings. Psychological Review, 88, 375-407.

Monsell, S. (1985). Repetition and the lexicon. In A. W. Ellis (Ed.), Progress in the psychology of language (Vol. 2, pp. 147-195). London: Erlbaum.

Monsell, S., Matthews, G. H., \& Millek, D. C. (1992). Repetition of lexicalization across languages; A further test of locus of priming. Quarterly Journal of Experimental Psychology, 44A, 762-784.

MORTON, J., \& PATTERSON, K. E. (1980). A new attempt at interpretation, or an attempt at a new interpretation. In M. Coltheart, K. E. Patterson, \& J. Marshall (Eds.), Deep dyslexia (pp. 91-118). London: Routledge.

Nelson, D. L., ReED, V. S., \& McEvoy, C. L. (1977). Learning to order pictures and words: A model of sensory and semantic encoding. Journal of Experimental Psychology: Human Learning \& Memory, 3 , 485-497.

OldFIELD, R. C., \& WingField, A. (1965). Response latencies in naming objects. Quarterly Journal of Experimental Psychology, 17, $273-$ 281

Park, S. M., \& Gabrieli, J. D. E. (1995). Perceptual and nonperceptual components of implicit memory for pictures. Journal of Experimental Psychology: Learning, Memory, \& Cognition, 21, 1583-1594.

Patterson, K. E., \& Coltheart, V. (1987). Phonological processes in reading: A tutorial review. In M. Coltheart (Ed.), Attention and performance $X I I$ (pp. 421-447). London: Erlbaum.

Patterson, K. E., \& Shewel L, E. (1987). Speak and spell: Dissociation and word-class effects. In M. Coltheart., G. Sartori, \& R. Job (Eds.), The cognitive neuropsychology of language (pp. 273-294). London: Erlbaum.

Potter, M. C., \& Faulconer, B. (1975). Time to understand pictures and words. Nature, $253,437-438$.

Price, C. J., \& Humphreys, G. W. (1989). The effects of surface detail on object categorization and naming. Quarterly Journal of Experimental Psychology, 41 A, 797-828.

Riddoch, M. J., \& Humphreys, G. W. (1987a). Picture naming. In G. W. Humphreys \& M. J. Riddoch (Eds.), Visual object processing. A cognitive neuropsychological approach (pp. 107-143). London: Erlbaum.

Riddoch, M. J., \& Humphreys, G. W. (1987b). Visual object processing 
in optic aphasia: A case of semantic access agnosia. Cognitive Neuropsychology, 4, 131-185.

ROEDIGER, H. L., III, \& SRINIVAS, K. (1993). Specificity of operations in perceptual priming. In P. Graf \& M. E. J. Masson (Eds.), Implicit memory: New directions in cognition, development and neuropsychology (pp. 17-48). London: Erlbaum.

Rosch, E. (1975). Cognitive representations of semantic categories. Journal of Experimental Psychology: General, 104, 192-233.

SARTORI, G., \& JOB, R. (1988). The oyster with four legs: A neuropsychological study of the interaction of visual and semantic information. Cognitive Neuropsychology, 5, 105-132.

Sartori, G., Job, R., \& Coltheart, M. (1993). The neuropsychology of visual semantics. In D. E. Meyer \& S. Kornblum (Eds.), Attention \& Performance XIV. Hillsdale, NJ: Erlbaum.

Scarborough, D. L., Gerard, L., \& Cortese, C. (1979). Accessing lexical memory: The transfer of word repetition effects across task and modality. Memory \& Cognition, 7, 3-12.

SCHACTER, D. L. (1990). Perceptual representation systems and implicit memory: Toward a resolution of the multiple memory systems debate. In A. Diamond (Ed.), The development of neural bases of higher cognitive functions (Annals of the New York Academy of Sciences, Vol. 608, pp. 543-571). New York: New York Academy of Sciences.

Seymour, P. H. K. (1979). Human visual cognition. London: Collier MacMillan.

Shallice, T. (1988). From neuropsychology to mental structure. New York: Cambridge University Press.

SHERIDAN, J., \& HUMPHREYS, G. W. (1993). A verbal-semantic categoryspecific recognition impairment. Cognitive Neuropsychology, 10, 143-184.

Silveri, M. C., \& GaINotTI, G. (1988). Interaction between vision and language in a category-specific semantic impairment. Cognitive Neuropsychology, 5, 677-709.

Smith, M. C., \& MageE, L. E. (1980). Tracing the time course of picture-word processing. Journal of Experimental Psychology: General, $109,373-392$.

SNODGRASS, J. G. (1984). Concepts and their surface representations. Journal of Verbal Learning \& Verbal Behaviour, 23, 3-22.

Snodgrass, J. G., \& MCCullough, B. (1986). The role of visual similarity in picture categorization. Journal of Experimental Psychology: Learning, Memory, \& Cognition, 12, 147-154.

SNOdGRASS, J. G., \& VANDERWART, M. (1980). Standardized set of 260 pictures: Norms of name agreement, usage agreement, familiarity, and visual complexity. Journal of Experimental Psychology: Human Learning \& Memory, 6, 174-215.

Sperber, R. D., McCauley, C., Ragain, R. D., \& Weil, C. M. (1979). Semantic priming effects on picture and word processing. Memory $\&$ Cognition, 7, 339-345.

Strain, E., Patterson, K., \& Seidenberg, M. S. (1995). Semantic effects in single-word naming. Journal of Experimental Psychology: Learning, Memory. \& Cognition, 21, 1140-1154.

Theios, J., \& AMrhein, P. C. (1989). Theoretical analysis of the cognitive processing of lexical and pictorial stimuli: Reading, naming, and visual and conceptual comparisons. Psychological Review, 96, 1, 5-24.

VANDERWART, M. (1984). Priming by pictures in lexical decision. Journal of Verbal Learning \& Verbal Behaviour, 23, 67-83.

VItкоvitch, M., \& HumphreYs, G. W. (1991). Perseverant responding in speeded picture naming: It's in the links. Journal of Experimental Psychology: Learning, Memory, \& Cognition, 17, 664-680.

VitKovitch, M., HuMPhreys, G. W., \& Lloyd-Jones, T. J. (1993). On naming a giraffe a zebra: Picture naming errors across different object categories. Journal of Experimental Psychology: Learning, Memory, \& Cognition, 19, 243-259.

Vriezen, E., Moscovitch, M.. \& Bellos, S. (1995). Priming effects in semantic classification tasks. Journal of Experimental Psychology: Learning, Memory, \& Cognition, 21, 933-946.

WARREN, C. E. J., \& MORTON, J. (1982). The effects of priming on picture recognition. British Journal of Psychology, 73, 117-130.

WELDON, M. S., \& RoEDIGER, H. L., III (1987). Altering retrieval demands reverses the picture superiority effect. Memory \& Cognition, $15,269-280$.
WHEELDON, L. R., \& MONSELL, S. (1992). The locus of repetition priming of spoken word production. Quarterly Journal of Experimental Psychology, 44A, 723-761.

\section{NOTES}

1. In fact, two ANCOVAs were carried out, each using different measures of name frequency. The first used the value relating to the singular or mass noun only. The second used the stem frequency count, which refers to words having the same stem and/or meaning and belonging to the same major word class, differing only in inflection and/or spelling. Since the results obtained were identical, only the second analysis is reported for this and subsequent experiments. A further point to note is that $\log$ name frequency values were used rather than untransformed name frequency values (see Oldfield \& Wingfield, 1965). This was the case for all reported experiments.

2. Full details of all ANCOVAs and of all word-nonword and error analyses (see later) for Experiments 1, 2, and 3 may be obtained from the first author upon request

3. It could be argued that these differences are due to contrasting name agreement. Since we had a relatively liberal criterion of name agreement low name agreement may contribute to any baseline and/or priming effects, with there being less name agreement for vegetable and fruit categories. However, in this case, it would not be name agreement as is usually defined (i.e., that there exist alternative names for an object; e.g., oven/cooker) since individual fruit and vegetables do not have alternative names. Rather, it reflects a difficulty in putting names to objects that look similar (e.g., plum/grape), which is concomitant with manipulating visual similarity. That is, it is a problem of making within-category perceptual discriminations. Thus, a slightly less conservative name agreement criterion is not a confound as such; rather, by this definition, it is a function of visual similarity. Furthermore, relevant to this, three procedures used in the present experiment should be noted. First, latencies $\pm 2 S D$ s from each subject's mean in each condition were counted as errors, and, following this, items where accuracy was $<62.5 \%$ were dropped from the analyses (this criterion still meant that there were at least $10 \mathrm{RT}$ were gathered for each cell in the subject and item analyses). Second each analysis was carried out twice: once dropping items with fewer than $10 \mathrm{RTs}$, and once using the RTs left after counting those RTs less than or greater than $2 S D$ s as errors, no matter how few RTs were left for each item. The outcome of both sets of analyses was the same in all cases, since these procedures affected only a small percentage of total items. In addition, as reported above, item analyses were carried out

4. A repeated measures ANOVA was carried out on RTs to categorized prime pictures and named target pictures. The factors were task (categorization vs. naming) and category (structurally similar vs. structurally dissimilar). There was a main effect of task, with longer RTs for naming than for categorization $\left[F_{1}(1,31)=26.8, M S_{\mathrm{e}}=31,833, p\right.$ $\left..0001 ; F_{2}(1,94)=81.1, M S_{\mathrm{e}}=12,987, p<.0001\right]$. There was also a main effect of category, with longer RTs to structurally similar items than to structurally dissimilar items $\left[F_{1}(1,31)=134.3, M S_{\mathrm{e}}=12,526\right.$, $\left.p<.0001 ; F_{2}(1,94)=144.5, M S_{\mathrm{e}}=13,923, p<.0001\right]$. Finally, the task $\times$ category interaction was significant $\left[F_{1}(1,31)=25.4, M S_{\mathrm{e}}=\right.$ $\left.13,760, p<.0001 ; F_{2}(1,94)=23.0, M S_{\mathrm{e}}=12,987, p<.0001\right]$. Planned comparisons showed no significant differences between structurally dissimilar item RTs across the two tasks ( $731 \mathrm{vs.} 790 \mathrm{msec}$, for categorization and naming, respectively). However, there was a significant difference between tasks for structurally similar items ( $p s<.01 ; 856$ vs. $1,123 \mathrm{msec}$, for categorization and naming, respectively). Thus, the category difference is substantially greater for naming than for categorization. Error data followed the same trends as RTs; there were no speedaccuracy tradeoffs.

5. We calculated power using the formulas of Erdfelder et al. (1996). In general, Erdfelder et al. and the tables published by Cohen agree quite well. However, it should be noted that Cohen underestimates the power and overestimates the sample sizes systematically if the total sample size and the term $v+u+1$ differ (where $v$ and $u$ denote the numerator and denominator, respectively; see also Koele, 1982).

6 . In the unpublished pilot study, 30 subjects received a block of 30 matched structurally similar and structurally dissimilar items and a 
block of 30 matched structurally similar and structurally dissimilar items, with 30 additional same-category fillers. Block order was counterbalanced, and the same lists of items were rotated across "fillers" versus "no fillers" conditions. Data were collated and the data-trimming methods employed in the present experiments were used. ANOVAs were carried out on the data (by subjects and by items). The factors were category (structurally similar vs. structurally dissimilar) and list (fillers vs. no fillers). There was a main effect of category, with longer RTs to structurally similar items $\left[F_{1}(1,29)=79.33, M S_{\mathrm{e}}=6,909, p<.0001\right.$; $\left.F_{2}(1,58)=10.81, M S_{\mathrm{e}}=50,425, p<.005\right]$. There was a main effect of list, by items only $\left[F_{1}(1,29)=2.52 ; F_{2}(1,58)=5.02, M S_{\mathrm{e}}=21,891\right.$, $p<.05]$. There was no category $\times$ list interaction $\left[F_{1}(1,29)=1.98\right.$; $F_{2}(1,58)=1.99$, which would indicate an increased difference between structurally similar and structurally dissimilar items when same-category fillers were inserted into the lists.

7. Baseline RTs to structurally similar target objects were as follows: in Experiment 1, 1,174 and 1,172 msec (for the picture-picture and word-picture conditions); in Experiment 2, 1,182 and 1,065 msec (for the word-picture and picture-picture conditions); in Experiment 2a, $1,214 \mathrm{msec}$. The corresponding magnitudes of the repetition priming effects were 190 and $178 \mathrm{msec}$ (Experiment 1), 107 and $2 \mathrm{msec}$ (Experiment 2), and $59 \mathrm{msec}$ (Experiment 2a). Baseline picture naming RTs were slowest in Experiment 2a; however, in that experiment, priming was not reliably larger for structurally similar items than for structurally dissimilar items. Also, for structurally dissimilar items, baseline RTs for picture categorization and naming were similar, although the amount of priming differed. The baseline and corresponding priming effects for picture categorization were $762 \mathrm{msec}$ and $5 \mathrm{msec}$ (Experiment 3, picture prime - picture target condition) and 771 and $4 \mathrm{msec}$ (Experiment 3 , word prime-picture target condition). These compare with the following baseline and corresponding priming effects for picture naming: 777 and $34 \mathrm{msec}$ (Experiment 2, picture prime-picture target condition) and 802 and 50 msec (Experiment 2, word prime picture tar- get condition). Again, there is no clear correspondence between initial baseline and amount of priming. We conclude that the magnitude of priming is a function of the processes involved, and not simply a consequence of overall RTs.

\section{APPENDIX}

List of Items Used in Experiments 1, 2, and 3

Category Items

Clothing shirt, sock, coat, jacket, tights, watch, earring, hat jumper, trousers, bra, dress, shoes, belt, vest, scarf, tie, glove, waistcoat, ring, skirt, blouse, glasses, handbag

Furniture dresser, mirror, ironing board, hoover, chair, stool, lamp, bed, vase, telephone, television, sofa, shelves, clock, cupboard, rug, table, desk, fridge, piano, stereo, toaster, cooker, ashtray

Fruit pear, prune, avocado, pineapple, pomegranate, melon, olive, cherry, date, fig, banana, strawberry, coconut, lemon, apple, raspberry, grapefruit, grapes, gooseberry, orange, peach, plum, apricot, pumpkin

Vegetables sweetcorn, potato, asparagus, carrot, leek, lettuce, onion, bean, turnip, radish, watercress, artichoke, garlic, aubergine, mushroom, courgette, rice, pepper, celery, parsley, cucumber, radish, sprout, marrow

(Manuscript received December 13, 1995; revision accepted for publication July 29,1996 .) 